\title{
The microbial community of the gut differs between piglets fed sow milk, milk replacer or bovine colostrum
}

\author{
Ann-Sofie R. Poulsen ${ }^{1 *}$, Nadieh de Jonge ${ }^{2}$, Sugiharto Sugiharto ${ }^{3}$, Jeppe L. Nielsen ${ }^{2}$, Charlotte Lauridsen ${ }^{1}$ \\ and Nuria Canibe ${ }^{1}$ \\ ${ }^{1}$ Department of Animal Science, Faculty of Science and Technology, Aarbus University, 8830 Tjele, Denmark \\ ${ }^{2}$ Department of Chemistry and Bioscience, Center for Microbial Communities, Aalborg University, 9220 Aalborg, Denmark \\ ${ }^{3}$ Faculty of Animal and Agricultural Sciences, Diponegoro University, Semarang, Central Java 50275, Indonesia
}

(Submitted 6 July 2016 - Final revision received 24 December 2016 - Accepted 16 January 2017-First published online 2 May 2017)

\section{Abstract}

The aim of this study was to characterise the gut microbiota composition of piglets fed bovine colostrum (BC), milk replacer (MR) or sow milk (SM) in the post-weaning period. Piglets ( $n 36$ ), 23-d old, were randomly allocated to the three diets. Faecal samples were collected at 23 , 25, 27 and $30 \mathrm{~d}$ of age. Digesta from the stomach, ileum, caecum and mid-colon was collected at $30 \mathrm{~d}$ of age. Bacterial DNA from all samples was subjected to amplicon sequencing of the $16 \mathrm{~S}$ rRNA gene. Bacterial enumerations by culture and SCFA analysis were conducted as well. BC-piglets had the highest abundance of Lactococcus in the stomach $(P<0.0001)$ and ileal $(P<0.0001)$ digesta, whereas SM-piglets had the highest abundance of Lactobacillus in the stomach digesta $(P<0.0001)$. MR-piglets had a high abundance of Enterobacteriaceae in the ileal digesta $(P<0.0001)$ and a higher number of haemolytic bacteria in ileal $(P=0.0002)$ and mid-colon $(P=0 \cdot 001)$ digesta than SM-piglets. BC-piglets showed the highest colonic concentration of iso-butyric and iso-valeric acid $(P=0 \cdot 02)$. Sequencing and culture showed that MR-piglets were colonised by a higher number of Enterobacteriaceae, whereas the gut microbiota of BC-piglets was characterised by a change in lactic acid bacteria genera when compared with SM-piglets. We conclude that especially the ileal microbiota of BC-piglets had a closer resemblance to that of SM-piglets in regard to the abundance of potential enteric pathogens than did MR-piglets. The results indicate that BC may be a useful substitute for regular milk replacers, and as a feeding supplement in the immediate post-weaning period.

\section{Key words: Bovine colostrum: Gut microbiota: Undersized piglets: $16 \mathrm{~S}$ rRNA gene sequencing}

The increased litter size of the modern pig industry has negatively influenced piglet viability. Large litters show great variation in within-litter birth weights and are accompanied by an increased number of low birth-weight piglets. Undersized piglets have difficulties competing with heavier littermates, and experience reduced growth rates and increased morbidity and mortality ${ }^{(1)}$. To ensure adequate feed intake of undersized piglets and hence improve weight gain and survival chances, providing milk replacers has been implemented by many pig farmers ${ }^{(2)}$. However, the gastrointestinal tract of undersized piglets may be immature compared with that of normal-weight piglets, influencing optimal nutrient digestion and absorption.

Diet is known to influence gut maturation ${ }^{(3)}$. Besides maturing functional entities of the intestinal tissues, gut maturation also includes the establishment of a gastrointestinal microbiota ${ }^{(4)}$. The gastrointestinal microbiota is appreciated as an important inhabitant of the body, being highly involved in host defensive mechanisms. The local defensive mechanisms of the gut microbiota include competing with pathogens for mucosal binding sites and nutrients, production of antimicrobial-like agents and elimination of noxious substances ${ }^{(5,6)}$. Furthermore, microbial colonisation of the gut stimulates local immune cell proliferation, hence playing a key role in the maturation of the innate and adaptive immune system. As the gut microbiota influences animal health, choosing a diet in favour of a beneficial microbiota may be crucial. This is important especially at the time of microbiota establishment after birth, as the early bacterial colonisers in the gut are involved in the shaping of the gut microbiota in later life ${ }^{(7)}$.

Colostrum is the milk secreted during the first $24-48 \mathrm{~h}$ following parturition $^{(8,9)}$. Bovine colostrum (BC) is a by-product from the dairy industry, available in excess amounts, and a rich source of biologically active compounds ${ }^{(10,11)}$. The major bio-active compounds are growth factors such as insulin-like growth factor-I and II, epidermal growth factor and transforming growth

Abbreviations: BC, bovine colostrum; BC-fed, piglets separated from the sow and fed powdered BC; ETEC, enterotoxigenic Escherichia coli; LAB, lactic acid bacteria; MR-fed, piglets separated from the sow and fed a commercial porcine milk replacer powder; OTU, Operational Taxonomical Units; SM-fed, piglets fed sow milk.

* Corresponding author: A. R. Poulsen, fax +45 871542 49, email ann-sofie.riispoulsen@anis.au.dk 
factor- $\beta 1$ and $\beta 2$, and antimicrobials such as immunoglobulins ${ }^{(12)}$. In preterm born piglets, $\mathrm{BC}$ has been reported to increase the activity of specific brush-border enzymes, improve intestinal health and decrease severity of necrotising enterocolitis when compared with feeding milk formula ${ }^{(13)}$. In term born piglets, provision of $\mathrm{BC}$ rather than milk replacer reduced the intestinal colonisation of enterotoxigenic Escherichia coli and modulated the expression of Toll-like receptor-4 (TLR-4) and IL-2, whereas no difference between $\mathrm{BC}$ and natural rearing with the sow was observed ${ }^{(14)}$. Furthermore, newly weaned piglets have shown improved growth performance $^{(15)}$ and intestinal mucosal restoration ${ }^{(16)}$ when their standard weaning diet was supplemented with BC.

The effect of $\mathrm{BC}$ on the composition of the gastrointestinal microbiota remains to be explored. The aim of the present study was therefore to taxonomically and quantitatively characterise the early colonisation of the gastrointestinal microbial community in piglets fed sow milk, milk replacer (originating from bovine milk) or $\mathrm{BC}$ in the 1st week post-weaning. We hypothesised that the gastrointestinal microbial community of piglets fed $\mathrm{BC}$ would have closer resemblance to that of piglets fed sow milk than would piglets fed milk replacer.

\section{Methods}

\section{Study design}

The present study was conducted according to the ethical license obtained from the Danish Animal Experiments Inspectorate, Ministry of Food, Agriculture and Fisheries, Danish Veterinary and Food administration. National guidelines on experimental animal housing, care and killing procedure were followed. The study was performed at the experimental facility at the Department of Animal Science (Foulum, Aarhus University).

A total of thirty-six piglets ((Duroc $\times$ (Danish Landrace $\times$ Yorkshire); mixed females and males) from four different sows were included in the study. The sows originated from the herd at Aarhus University Foulum, Denmark. All piglets were housed with their dams until the beginning of the experiment at $23 \mathrm{~d}$ of age. The thirty-six piglets (nine piglets from each sow) were then randomly assigned to one of the following treatment groups (three piglets from each sow per treatment): (a) kept with the sow for the whole experimental period (SM-fed); (b) separated from the sow and fed a commercial porcine milk replacer powder (Grifor; Hatting KS) (MR-fed); (c) separated from the sow and fed powdered BC (European Colostrum Industry S.A.) (BC-fed). The chemical composition of the sow milk, milk replacer and $\mathrm{BC}$ is shown in Table 1.

Piglets separated from the sow were transported to an experimental stable at Research Center Foulum, Aarhus University and housed in pens $(1.45 \times 1.70 \mathrm{~m})$ in groups of three littermates until $30 \mathrm{~d}$ of age (end of experiment). Piglets were randomly allocated to the dietary treatments. All pens were padded with rubber mats and piglets had access to rooting material. Stable temperature was $24^{\circ} \mathrm{C}$. Each pen was equipped with an automated wet feeder (Mambo Automix 25; Wit-Mambo Inc.) from which the piglets received ad libitum feeding. Piglets had permanent access to fresh water. The powdered $\mathrm{BC}$ and
Table 1. Analysed and assumed chemical compositions of sow milk $(\mathrm{SM})$, milk replacer (MR) and bovine colostrum $(\mathrm{BC})^{\star}$

\begin{tabular}{lrcr}
\hline & \multicolumn{3}{c}{ Dietary group } \\
\cline { 2 - 4 } Items & SM & MR & BC \\
\hline DM (\%) & $17.9 \dagger$ & 95.0 & 96.1 \\
Protein (\%) & $5.1 \dagger$ & 22.1 & 68.2 \\
Fat (\%) & $6.5 \dagger$ & 13.2 & 2.0 \\
Ash (\%) & $1.0 \ddagger$ & 6.8 & 6.0 \\
Immunoglobulins (\% of DM)§ & & & \\
IgG & 0.11 & 0.05 & 38.4 \\
IgA & 2.18 & 0.01 & 3.59 \\
IgM & 0.56 & ND & 2.52 \\
\hline
\end{tabular}

ND, not detected

* Chemical analyses (DM, protein, fat and ash) were performed by Eurofins Steins Laboratory A/S.

$\uparrow$ Adopted from Lauridsen \& Danielsen ${ }^{(17)}$.

$\ddagger$ Adopted from Aguinaga et al. ${ }^{(18)}$

$\S$ Immunoglobulin concentrations are adopted from Sugiharto et al. ${ }^{(14)}$.

MR were dissolved in approximately $45^{\circ} \mathrm{C}$ warm water in the automated feeder (approximate final DM percentage: BC 20 and MR 15\%). To get the piglets accustomed to the feeding machine, they were fed one portion of sow milk in the trough of the machine upon arrival to the pen. SM-fed piglets suckled their dams until $30 \mathrm{~d}$ of age (end of experiment). In an attempt to minimise the impact of other factors than the planned dietary intervention, SM-fed piglets were transported exactly as the BC-fed and MR-fed piglets before returning to the sow. This ensured that all piglets were subjected to similar stress conditions due to transportation. Furthermore, to reduce the influence of the microbial load in the pen environment on the results, faecal matter from the corresponding dam was collected from the sow pen and spread on the floor of the MR- and BCfed piglets' pens daily. In this way, all three groups continued to be exposed to the faecal microbiota of their respective dams on a daily basis.

\section{Sample and data collection}

Piglets were individually weighed at 23 and $30 \mathrm{~d}$ of age. BC and MR consumption was recorded daily as powder provided minus leftovers from the automated wet feeder (determined by freezedrying). The clinical condition of the piglets was evaluated daily, including occurrence of diarrhoea.

Faecal samples were collected via rectal stimulation on day 23 (before transportation), 25, 27 and 30. All piglets were euthanised at $30 \mathrm{~d}$ of age; the abdomen was incised and the gastrointestinal tract removed. Total digesta content from the stomach, proximal and distal small intestine (two equal lengths), caecum, and proximal, mid and distal colon (three equal lengths) were collected immediately after killing. Subsamples of digesta from the respective segments and faeces were taken and stored at $-20^{\circ} \mathrm{C}$ for organic acid analysis (stomach, distal small intestine, caecum and mid colon) and snap-frozen in liquid $\mathrm{N}_{2}$ and stored at $-80^{\circ} \mathrm{C}$ for $16 \mathrm{~S}$ rRNA gene sequencing (stomach, distal small intestine and mid colon). Bacterial enumeration by culture was performed on a fresh subsample of faeces and digesta (stomach, distal small intestine, caecum and mid colon). 


\section{DM and organic acid analysis}

DM content of digesta was determined by freeze-drying using a ScanVac Coolsafe 55 (Labogene ApS). Concentrations of the SCFA acetic, propionic, butyric, isobutyric, valeric and isovaleric acids, and lactic acid in faeces and digesta were quantified as previously described by Canibe et $a l .{ }^{(19)}$.

\section{Microbiological enumerations}

Approximately $1 \mathrm{~g}$ faecal material was suspended in $10 \mathrm{ml}$ pre-reduced salt medium ${ }^{(20)}$. The content was homogenised in a Smasher paddle blender (bioMérieux Industry) for 2 min. Approximately $5 \mathrm{~g}$ digesta were suspended in a flask containing $50 \mathrm{ml}$ pre-reduced salt medium. The flask content was transferred to a $\mathrm{CO}_{2}$ flushed bag and homogenised for $2 \mathrm{~min}$. A homogenate sample of $1 \mathrm{ml}$ was transferred to a Hungate tube containing $9 \mathrm{ml}$ pre-reduced salt medium and 10-fold dilutions were prepared using the technique previously described by Miller \& Wolin ${ }^{(21)}$. The samples were plated on selective and non-selective agar plates.

Enterobacteriaceae were enumerated on MacConkey agar (Merck 1.05465) after aerobic incubation for $1 \mathrm{~d}$. Yeasts were enumerated on malt, chlortetracycline and chloramphenicol agar (Merck 1.03753 (yeast extract), 1.05397 (malt extract), 1.07224 (bacto-pepton), 1.08337 (glucose), 1.01614 (agar-agar) and Oxoid Sr0177E) after aerobic incubation for $2 \mathrm{~d}$. Haemolytic bacteria were enumerated on blood agar (Oxoid Pb5039A) after aerobic incubation for $1 \mathrm{~d}$. Clostridium perfringens were enumerated using the pour-plate technique on tryptose sulfit cycloserine agar (Merck 1.11972, 1.00888) after anaerobic incubation for $1 \mathrm{~d}$. Lactic acid bacteria (LAB) were enumerated on de Man, Rogosa and Sharp agar (Merck 1.10660) after anaerobic incubation for $2 \mathrm{~d}$. Total anaerobic bacteria were enumerated in roll tubes containing pig colon fluid-glucose-cellobiose agar ${ }^{(20)}$ and incubated for $7 \mathrm{~d}$. Plates and roll-tubes were incubated at $37^{\circ} \mathrm{C}$.

\section{DNA extraction}

Samples for DNA extraction included forty-seven faecal samples (one sample was missing from the SM-fed group on day 25) from twelve piglets and seventy-two digesta (stomach, distal small intestine, mid colon) samples from twenty-four piglets. DNA was extracted with the E.Z.N.A. Stool DNA Kit (Omega Bio-Tek Inc.; VWR International) following a standard protocol with the following exception; bead beating was performed on a FastPrep FP120 (Bio 101 Savant/MP Biomedicals) for $2 \times 30$ s. DNA extract purity was evaluated with Nanodrop ND1000 (Thermo Scientific) and quantified fluorometrically with Qubit 3.0 HS dsDNA assay (Life Technologies; Thermo Fisher Scientific). DNA concentrations were normalised to $5 \mathrm{ng} / \mu \mathrm{l}$ by dilution.

\section{5 rRNA gene amplicon sequencing}

Amplicon libraries were generated by targeted amplification of the V1-V3 hypervariable regions of the bacterial 16S rRNA gene. The PCR reaction $(25 \mu \mathrm{l})$ contained $10 \mathrm{ng}$ template DNA, Platinum $^{\circledR}$ High Fidelity buffer $(\times 1)$, dNTP $(400 \mu \mathrm{m}$ of each),
$\mathrm{MgSO}_{4}(1.5 \mathrm{~mm})$ and Platinum ${ }^{\circledR}$ Taq DNA polymerase High Fidelity ( $1 \mathrm{U}$ ) and barcoded library adapters ( $400 \mathrm{~nm}$ ). V1-V3 primers: 27F AGAGTTTGATCCTGGCTCAG and 534R ATTA CCGCGGCTGCTGG. Thermocycler settings: initial denaturation at $95^{\circ} \mathrm{C}$ for $2 \mathrm{~min}$, thirty cycles of $95^{\circ} \mathrm{C}$ for $20 \mathrm{~s}, 56^{\circ} \mathrm{C}$ for $30 \mathrm{~s}, 72^{\circ} \mathrm{C}$ for $60 \mathrm{~s}$ and final elongation at $72^{\circ} \mathrm{C}$ for $5 \mathrm{~min}$. PCR reactions were run in duplicate for each sample and pooled afterwards. Purification of the amplicon libraries was performed using the Agencourt AMPure XP bead protocol (Beckman Coulter) and eluted in $23 \mu \mathrm{l}$ nuclease-free water. Individual libraries were quantified with Quant-iT HS dsDNA assay (Life Technologies) and quality checked on a Tapestation 2200 (Agilent). Libraries were pooled in equimolar concentrations, and diluted to 4 nм. The library pool was sequenced using an Illumina MiSeq (Illumina) and MiSeq reagent kit v3 $(2 \times 300 \mathrm{PE})$. Raw reads are available in the Sequence Read Archive (https://www.ncbi.nlm. nih.gov) under accession number SRP093961.

\section{Bioinformatic processing and analysis}

The obtained raw sequencing reads were quality filtered and trimmed using trimmomatic (version 0.32$)^{(22)}$, only keeping reads with a minimum length of $275 \mathrm{bp}$. The trimmed reads were merged using FLASH version 1.2.7 $7^{(23)}$ and read pairs between 425 and $525 \mathrm{bp}$ in length were formatted for use with the UPARSE workflow ${ }^{(24)}$. Reads were dereplicated and clustered into Operational Taxonomical Units (OTU) using USEARCH7 at $97 \%$ sequence similarity. Taxonomy was assigned using the RDPclassifier as implemented in QIIME ${ }^{(25)}$ with a minimum confidence of 0.8 and Greengenes (version 08-2013) as a reference database. Results were analysed in R studio (version 0.99.489 for Mac) using the Ampvis package ${ }^{(26)}$

\section{Statistical analyses}

Principal component analysis was performed on square root transformed OTU abundances. Significance of diet was tested on the first two principal components (PC) using the envfit parametric test and on the Bray-Curtis dissimilarity matrix using the Adonis test ${ }^{(27)}$. The parametric Wald-test ${ }^{(28)}$ was used to test for significant OTU abundance differences between the SM group and the MR and $\mathrm{BC}$ groups. The Benjamini-Hochberg procedure was used for adjusting $P$ values, and OTU with an adjusted $P<0.001$ were considered significantly different between the respective diets. A constrained (by diet) redundancy analysis including bacterial enumerations and organic acids was performed to check for potential correlations between bacterial enumerations, organic acids and sequencing data using the envfit parametric test ${ }^{(27)}$. Correlations were considered significant when $P<0.05$.

The impact of diet and age on bacterial and organic acid parameters, microbial richness, and Shannon diversity index were investigated by fitting the data to a linear mixed model using the lmer function from the lme 4 package ${ }^{(29)}$ using R studio (version 0.99.489 for Mac). Diet and age/intestinal segment were included as fixed effects, whereas pig and sow were included as random effects (by including random intercept terms) to account for multiple observations made on the same litter and on the same pig. When analysing the body weight variable, the piglets' body 
weight at the beginning of the experiment (day 23) was included as a co-variate. The fixed effects were tested using an $F$ test with Kenward-Roger approximation, where the reduced model was tested against the full model. This was done using the KRmodcomp function in the pbkrtest package ${ }^{(30)}$. When a fixed effect was found to be significant, a post hoc test was performed using the multcomp package and Bonferroni adjustment to correct for multiple comparisons ${ }^{(31)}$. Effects were considered significant when $P<0.05$ and as trends when $0.05 \leq P<0.10$.

\section{Results}

During the course of the experiment, one BC-fed piglet was euthanised due to vomitus and general weakness and one MRfed piglet died. At $30 \mathrm{~d}$ of age, SM-fed piglets weighed more than BC-fed $(P=0.016)$ and MR-fed piglets $(P=0.011)$ (Table 2). The diarrhoea incidence rate was highest in the MR-fed group (Table 2).

\section{Microbiome composition: 16S rRNA gene amplicon sequencing}

Sequencing of 119 samples yielded a total of 2090874 sequences. A sequencing depth of 5000 sequences was considered appropriate from rarefaction curves, excluding four samples from analysis (data not shown). Recovered sequences clustered into 2485 OTU, which were classified into thirty-four bacterial phyla, 154 families and 271 genera. Eight phyla had an overall relative abundance above $1 \%$.

\section{Faecal microbiota}

The relative abundance of the eight most abundant phyla (relative abundance $>1 \%$ ) and twenty most abundant genera are presented in Fig. 1(A) and (B). Irrespective of diet and age, Firmicutes and Bacteroidetes dominated the communities. Prevotella and Oscillospira were the most abundant and stable genera both regarding diet and age. Of the twenty most abundant genera, ten belonged to the phylum Bacteroidetes and nine to the phylum Firmicutes. The microbial community richness was not influenced by diet or age (Fig. 1(C) and online
Supplementary Fig. S1(a)). The Shannon diversity was higher in MR-fed compared with BC-fed piglets $(P=0.015$; Fig. 1(D)). There was a significant effect of diet on the overall faecal microbial community composition of the three dietary groups on days $25\left(P_{\text {adonis }}=0.01\right)$ and $30\left(P_{\text {adonis }}=0.008\right)$ (Fig. 2$)$. However, no OTU were found to differ significantly in their read abundances between diets.

\section{Digesta microbiota}

Fig. 3(a) and (b) presents the eight most abundant phyla and twenty most abundant genera of the microbial communities of the stomach, distal small intestine and mid-colon. Irrespective of diet, the microbial communities of the stomach and mid-colon were dominated by Firmicutes, followed by Bacteroidetes. The distal small intestinal community was dominated by Firmicutes in SM-fed piglets, Firmicutes and Proteobacteria in MR-fed piglets, and Firmicutes followed by Proteobacteria and Actinobacteria in BC-fed piglets. Overall, Lactobacillus and Prevotella were the most dominating genera in the stomach and mid colon. In addition, Mitsuokella was the third most dominating genus in the stomach of BC-fed piglets. The microbial community of the distal small intestine was dominated by Lactobacillus (most pronounced in SM-fed piglets) and Enterobacteriaceae in MR-fed piglets. The community richness and Shannon diversity in the stomach, distal small intestine and mid colon did not differ between diets (Fig. 3(c) and (d) and online Supplementary Fig. S1(b)). Diet had a significant effect on the overall microbial community of the stomach $\left(P_{\text {adonis }}=0.001\right.$; Fig. $\left.4(\mathrm{a})\right)$, distal small intestine $\left(P_{\text {adonis }}=0.001 ;\right.$ Fig. 5(a) $)$ and mid colon $\left(P_{\text {adonis }}=0.001 ;\right.$ Fig. 6(a) $)$.

In the stomach, when comparing BC- to SM-fed piglets, six out of 551 OTU were found to have significantly different read abundances (Fig. 4(b)), all with a higher read abundance in BCfed piglets. OTU_72, belonging to Lactococcus, was the most significantly changed OTU, having a higher read abundance in BC-fed piglets $\left(P=5 \cdot 3 \mathrm{E}^{-6}\right.$; log2-fold change $\left.=-8 \cdot 4\right)$. Nine out of 566 OTU were found to have significantly different read abundances in MR- and SM-fed piglets (Fig. 4(c)). OTU_66, belonging to Lactobacillus, was the most significantly changed OTU, having a higher read abundance in SM-fed piglets $\left(P=2 \cdot 7 \mathrm{E}^{-11} ; \log 2\right.$-fold change $\left.=7 \cdot 5\right)$.

Table 2. Body weight at 23 (initial body weight) and $30 \mathrm{~d}$ of age, milk replacer and bovine colostrum powder intake in grams per pen, and diarrhoea incidence rate

(Least square means and $95 \%$ confidence intervals)

\begin{tabular}{|c|c|c|c|c|c|c|c|}
\hline \multirow[b]{3}{*}{ Items } & \multicolumn{6}{|c|}{ Dietary group* } & \multirow[b]{3}{*}{$P$} \\
\hline & \multicolumn{2}{|l|}{ SM } & \multicolumn{2}{|l|}{ MR } & \multicolumn{2}{|l|}{$\mathrm{BC}$} & \\
\hline & Least square mean & $95 \% \mathrm{Cl}$ & Least square mean & $95 \% \mathrm{Cl}$ & Least square mean & $95 \% \mathrm{Cl}$ & \\
\hline Body weight day $23(\mathrm{~kg})$ & 8.9 & $8 \cdot 5,9.4$ & $8 \cdot 1$ & $7.7,8.5$ & $8 \cdot 2$ & $7 \cdot 8,8.6$ & \\
\hline Body weight day $30(\mathrm{~kg})$ & $10 \cdot 2^{b}$ & $9 \cdot 8,10 \cdot 6$ & $9 \cdot 4^{\mathrm{a}}$ & $8.9,9.8$ & $9 \cdot 4^{\mathrm{a}}$ & $9.0,9.9$ & 0.005 \\
\hline Powder intake $(\mathrm{g})$ & ND & & 3980 & 2168,5791 & 2653 & 842,4465 & 0.25 \\
\hline Diarrhoea incidence rate† & 0.038 & & 0.172 & & 0.054 & & \\
\hline
\end{tabular}

SM, sow milk; MR, powdered porcine milk replacer; BC, spray-dried bovine colostrum powder; ND, not determined.

a,b Mean values within a row with unlike superscripts letters are significantly different $(P<0.05)$.

* Number of piglets: $\mathrm{SM}=12, \mathrm{MR}=11, \mathrm{BC}=11$.

† Defined as the ratio between the number of new cases of diarrhoea in the study period and the total number of days the piglets have been in risk (i.e. the number of days from the animal enters the study until the animal (a) shows clinical signs of diarrhoea, (b) dies or (c) the study ends) ${ }^{(32)}$. 
(A)

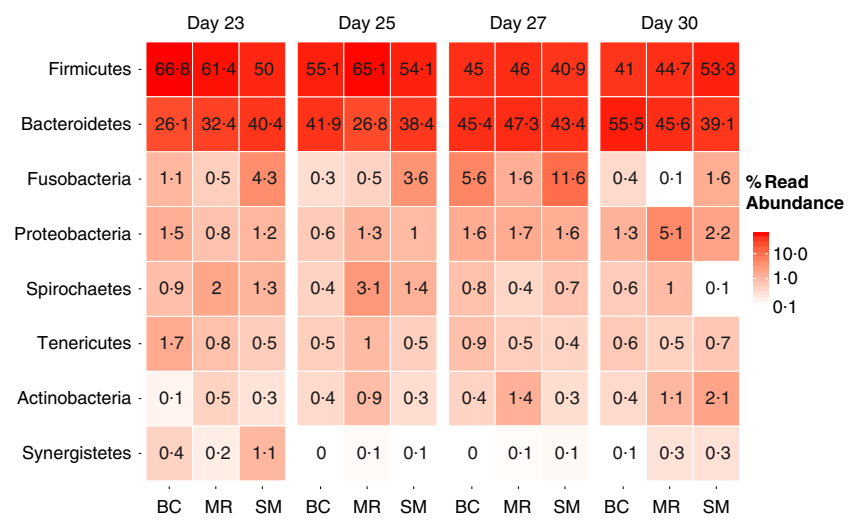

(B)

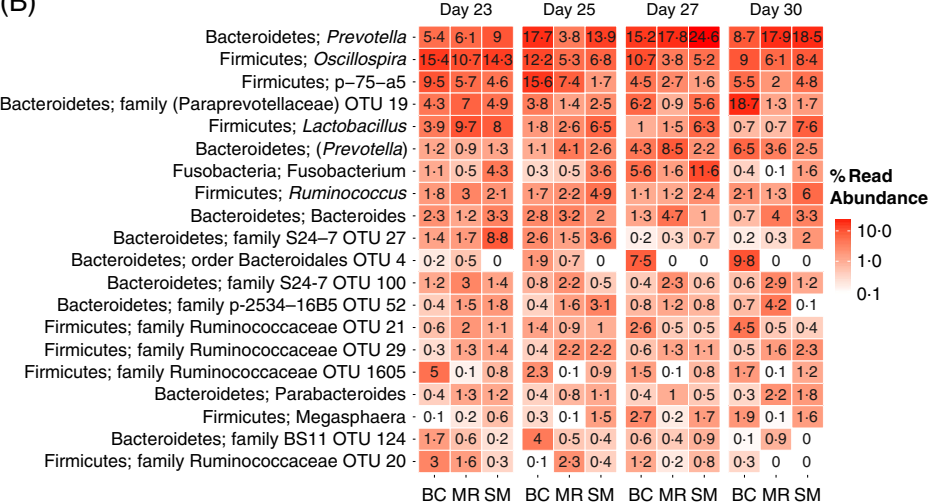

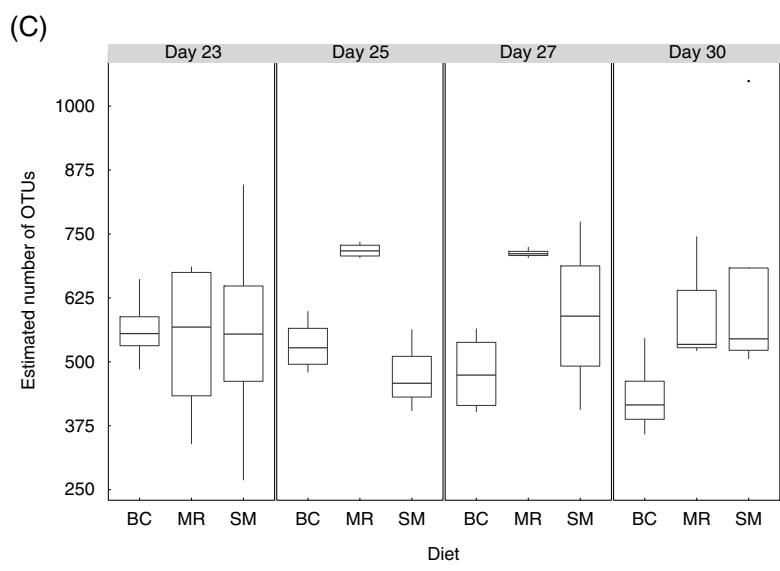

(D)

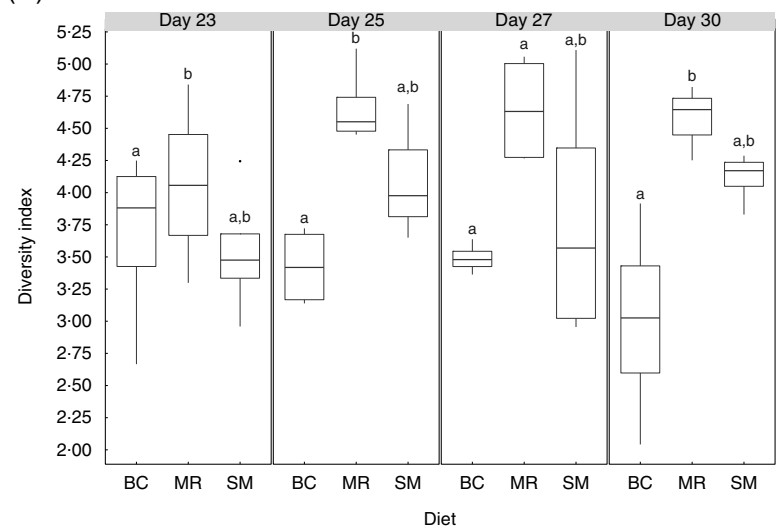

Fig. 1. Relative sequence abundances, estimated species richness and Shannon diversity index of faecal samples collected at $23,25,27$ and $30 \mathrm{~d}$ of age from piglets fed sow milk (SM; $n$ 15), milk replacer (MR; $n$ 15) or bovine colostrum (BC; $n$ 16). Heatmaps show the relative abundances (\%) of (A) the eight most abundant phyla and (B) the 20 most abundant genera in faecal samples. As some of the high abundant Operational Taxonomical Units (OTU) could not be classified to genus level, these are presented as their OTU number together with their best classification. Colours represent the relative abundances. Boxplots show the (C) estimated species richness and (D) Shannon diversity index. ${ }^{\mathrm{a}, \mathrm{b}}$ Values with unlike letters were significantly different $(P<0.05)$.

Clustering of MR-fed piglets was explained by the higher relative abundance of Enterobacteriaceae, clustering of SM-fed piglets was explained by Lactobacillus, and clustering of BC-fed piglets was explained by Lactococcus (Fig. 5(a)). Comparing BC- and MR-fed piglets with SM-fed piglets resulted in eleven out of 433 (BC fed) and 435 (MR fed) OTU having significantly different read abundances (Fig. 5(b) and (c)). As observed in the stomach, OTU_72 belonging to Lactococcus was found to be the most significantly changed OTU when comparing BC-fed and SM-fed piglets, having a higher read abundance in BC-fed piglets $\left(P=2 \cdot 2 \mathrm{E}^{-15} ; \log 2\right.$-fold change $\left.=-12 \cdot 0\right)$. OTU_6, belonging to Enterobacteriaceae, was the most significantly changed OTU when comparing MR- to SM-fed piglet $\left(P=4 \cdot 0 \mathrm{E}^{-10} ; \log 2\right.$-fold change $\left.=-8 \cdot 7\right)$, having a higher read abundance in MR-fed piglets.

Mid colon samples showed distinct grouping according to diet on PC3 (when plotted as a function of PC1) with MR-fed piglets clustering by themselves (Fig. 6(a)). Fourteen out of 802 OTU were found to have significantly different read abundances when comparing BC- and SM-fed piglets (Fig. 6(b)). The most significantly changed OTU was OTU_1 $\left(P=4.7 \mathrm{E}^{-12} ; \log 2\right.$-fold change $=5.6$ ), belonging to Lactobacillus, and was found to have a higher read abundance in SM-fed piglets. Comparing MR- and SMfed piglets resulted in thirteen out of 840 OTU being significantly different (Fig. 6(C)). OTU_47, belonging to Blautia, was the most significantly changed OTU $\left(P=1 \cdot 1 \mathrm{E}^{-13} ; \log 2\right.$-fold change $\left.=-9 \cdot 5\right)$ and was found to have a higher read abundance in MR-fed piglets.

\section{$\mathrm{DM}$ and $\mathrm{pH}$}

There was no difference in digesta $\mathrm{pH}$ between diets. DM content of digesta varied between diets, being dependent on gut segment (online Supplementary Table S1). There was no difference in DM content of digesta from the proximal small intestine and caecum between diets. DM content of digesta from the stomach $(P<0.0001)$, proximal colon $(P \leq 0.002)$ and mid colon $(P \leq 0.006)$ was highest in SM-piglets, whereas being higher in digesta from the distal small intestine $(P=0.049)$ of BC-piglets compared with MR-piglets. The lowest DM content of digesta from the distal colon was found in MR-piglets $(P \leq 0 \cdot 0003)$.

\section{Microbiological enumerations and concentration of organic acids}

Faeces. The number of $C$. perfringens was lower on day 30 compared with day $23(P=0.0006)$ and day $25(P=0.0008)$ for all diets, but there was no difference in any of the investigated microbial groups between diets (online Supplementary Table S2). 
(a)

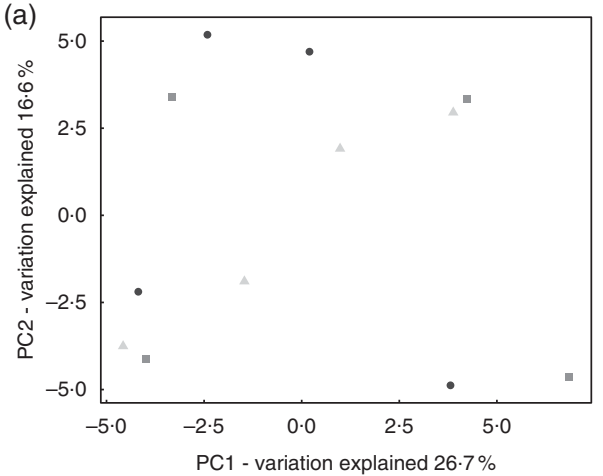

(c)

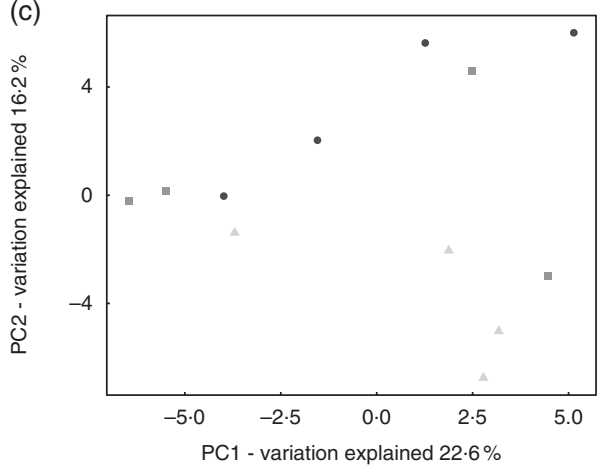

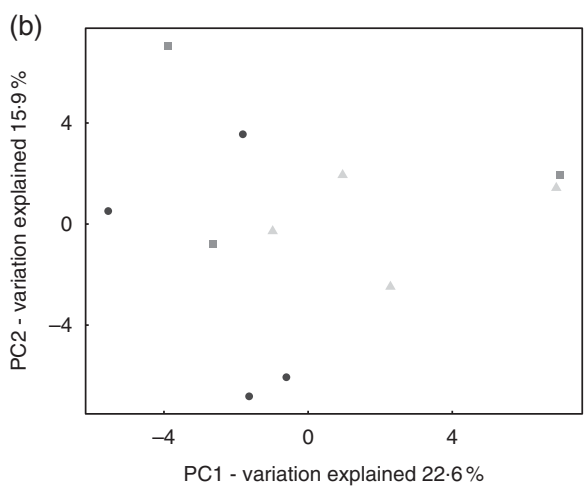

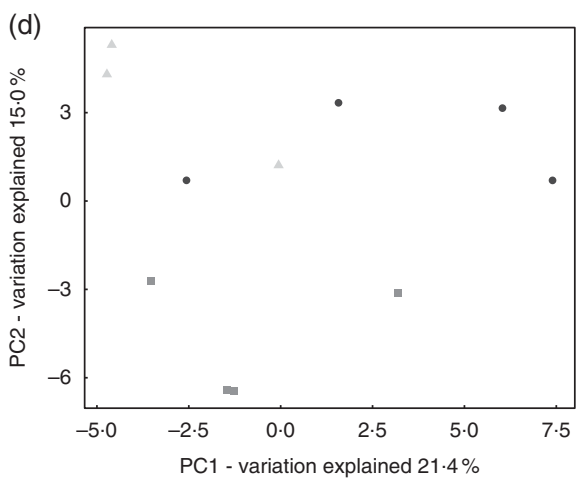

Fig. 2. Principal component analysis of square root transformed Operational Taxonomical Units (OTU) abundances in faecal samples ( $n$ 46) collected at (a) 23, (b) 25, (c) 27 and (d) $30 \mathrm{~d}$ of age displaying principal components (PC)1 and 2. Points are coloured according to diet.

Tendencies $(P=0.06)$ to higher LAB numbers in the SM-fed group, and higher yeast numbers in the MR-fed group were observed, though. Results of haemolytic bacteria have not been included due to the majority of counts being below detection level.

Faecal concentrations of acetic $(P \leq 0.004)$, propionic $(P \leq 0.013)$, butyric $(P \leq 0.0034)$ and their sum $(P \leq 0.001)$ were higher in BC-fed compared with SM- and MR-fed piglets (Table 3). The concentration of the sum of iso-butyric and iso-valeric acid was highest in BC-fed piglets $(P \leq 0.009)$ on days 25, 27 and 30. The concentrations of propionic $(P \leq 0.037)$, butyric $(P \leq 0.045)$ and the sum of acetic, propionic and butyric $(P \leq 0.045)$ acid were higher on days 25, 27 and 30 compared with day 23. The acetic acid concentration was higher on day $25(P=0.014)$ and day 30 ( $P=0.001)$ compared with day 23. In BC-piglets, the concentration of the sum of iso-butyric and iso-valeric acid was lowest on day 23 ( $P \leq 0.003)$.

Digesta. Haemolytic bacterial counts in digesta from the distal small intestine $(P=0.0002)$, caecum $(P=0.003)$ and mid colon $(P=0.001)$ were higher in MR-fed compared with SM-fed piglets (Table 4). The number of $C$. perfringens was higher in all segments of BC-fed $(P=0.041)$ compared with MR-fed piglets but similar to those in the SM-fed group.

The concentration of the sum of iso-butyric and iso-valeric acid in digesta from the colon $(P \leq 0.02)$ was higher in BC-fed compared with MR-fed piglets, whereas the caecal concentration was higher in SM-fed $(P=0.036)$ compared with MR-fed piglets (Table 5).

\section{Correlation between 165 rRNA gene sequences, organic acids and bacterial enumerations}

The constrained redundancy analysis performed on all samples (16S rRNA amplicon data) with fitted microbial enumerations and SCFA data (lactic acid omitted as detectable concentrations were only found in digesta) showed a clear separation between the different diets. Furthermore, various correlations between the different diets and microbial counts and SCFA concentrations were found (Fig. 7). Samples from the SM-fed piglets correlated with the number of $\mathrm{LAB}\left(r^{2} 0.11 ; P=0.02\right)$, whereas samples from the MR-fed piglets correlated with the number of haemolytic bacteria $\left(r^{2} 0.30 ; P=0.001\right)$ and yeasts $\left(r^{2} 0.25 ; P=0.001\right)$. Samples from the $\mathrm{BC}$-fed piglets correlated with the concentration of iso-butyric $\left(r^{2} 0.38 ; P=0.001\right)$, iso-valeric $\left(r^{2} 0.32 ; P=0.001\right)$, the sum of iso-butyric and iso-valeric acid $\left(r^{2} 0 \cdot 36 ; P=0.001\right)$, and to a lesser degree with the number of $C$. perfringens $\left(r^{2} 0 \cdot 10 ; P=0.02\right)$ and concentration of acetic $\left(r^{2} 0 \cdot 18 ; P=0 \cdot 002\right)$, propionic $\left(r^{2} 0 \cdot 15\right.$; $P=0.005)$, butyric $\left(r^{2} 0 \cdot 16 ; P=0.002\right)$, valeric $\left(r^{2} 0.21 ; P=0.001\right)$, and the sum of acetic, propionic and butyric acid $\left(r^{2} 0 \cdot 18\right.$; $P=0.002$ ).

\section{Discussion}

Several studies have investigated the effects of supplementary $\mathrm{BC}$ feeding on a variety of host protective functions in pigs $^{(13,16,33)}$. However, according to our knowledge, no studies have focused on the effect of $\mathrm{BC}$ on the gut microbiota when fed as the only source of nutrients. 
(a)

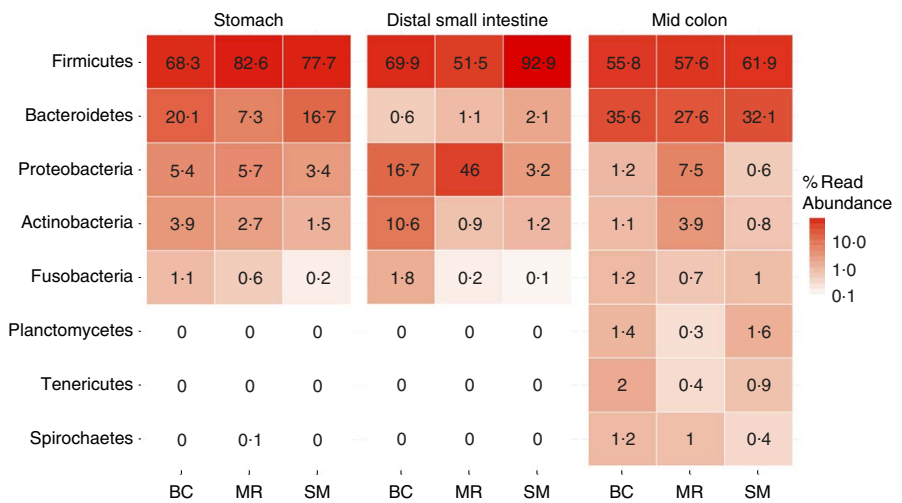

(b)

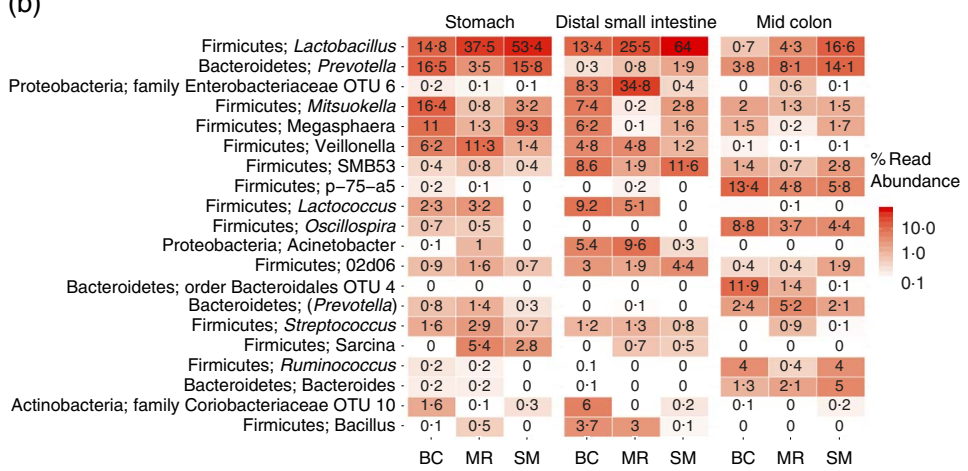

(c)

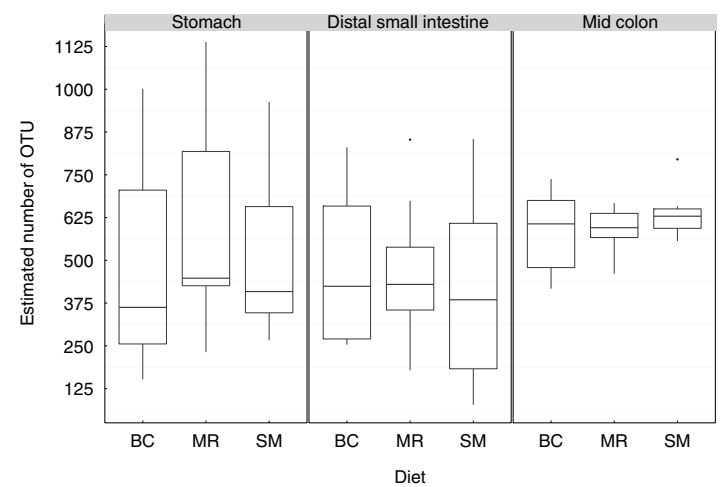

(d)

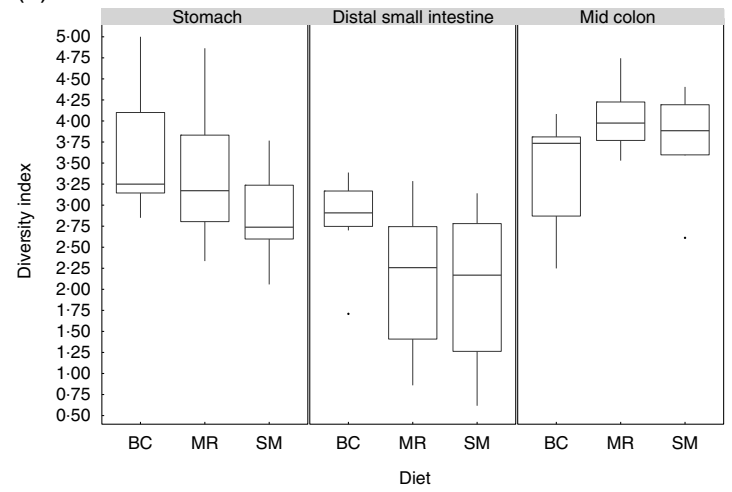

Fig. 3. Relative sequence abundances, estimated species richness and Shannon diversity index of stomach, distal small intestinal and mid colon digesta samples from piglets fed sow milk (SM; $n$ 23), milk replacer (MR; $n$ 23) or bovine colostrum (BC; $n$ 23). Heatmaps show the relative abundances (\%) of (a) the eight most abundant phyla and (b) twenty most abundant genera. As some of the high abundant Operational Taxonomical Units (OTU) could not be classified to genus level, these are presented as their OTU number together with their best classification. Colours represent relative abundances. Boxplots show the (c) estimated species richness and (d) Shannon diversity index.

The piglets in the SM- and BC-fed dietary groups were separated (weaned) from their dam at $23 \mathrm{~d}$ of age. As weaning is a highly stressful experience resulting in decreased feed intake and nutrient digestion capacity $^{(34)}$, the piglets in the present study, weaned at a relatively young age, were used as models for weak piglets in regards to having an unstable (immature) intestinal microbiota, suboptimal nutrient digestion and impaired immune status. Hence, the animals were regarded as suitable models when the aim was to study the impact of dietary components on the gastrointestinal microbial communities.

The microbial community is known to vary in composition according to gastrointestinal segment ${ }^{(35)}$, and samples were therefore collected from different locations along the gastrointestinal tract in the present study. In addition, to be able to follow the development of the microbiota from the same pigs over the course of the experiment, faecal samples were collected as well. Using $16 \mathrm{~S}$ rRNA gene sequencing, we showed that there were clear differences in the microbial communities from piglets fed different milk-based diets. As expected, the microbial communities were gut-region dependent, and the diets had different effects on the microbial community in the different regions of the gastrointestinal tract. The present results showed a clear influence of diet on the microbial communities of the stomach, small intestine and colon.
Diet did not influence the faecal microbial community to the same level as the digesta communities, suggesting that the faecal microbiota may need longer time to adjust in order to become diet specific.

The higher abundance of LAB genera as for example Lactococcus and Leuconostoc seen in BC-fed piglets was not observed in MR-fed piglets. An in vitro study by Champagne et al. ${ }^{(36)}$ showed a stimulating effect of $\mathrm{BC}$ on LAB growth rates, suggestively due to the oligosaccharides found in colostrum. As $\mathrm{BC}$ has a higher content of oligosaccharides than mature milk $^{(37)}$, such oligosaccharides might be the reason why BC-fed and not MR-fed piglets were found to have a higher read abundance of LAB as Lactococcus, Mitsuokella and Leuconostoc in their stomach and small intestinal digesta than SM-fed piglets.

Compared with the SM-fed piglets, the microbial communities of the stomach and small intestine of BC-fed piglets indicated a shift in LAB genera. OTU belonging to Lactococcus, Leuconostoc, Streptococcus and Carnobacterium were more abundant in BC-fed piglets, whereas the LAB of SM-fed piglets were mainly dominated by Lactobacillus. Lactococcus sp. is not part of the commensal pig gut microbiota, but has been reported to have bacteriocin producing properties ${ }^{(38)}$. Lactococcus and Leuconostoc have most frequently been associated with fermented dairy products; Carnobacterium has been found in dairy products, 
(a)

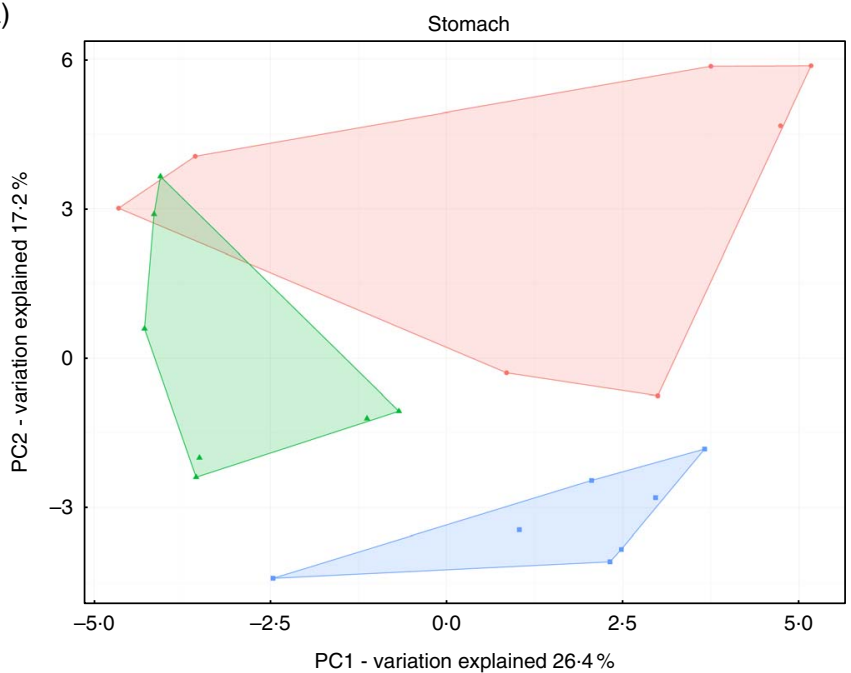

(b)

Firmicutes; Lactococcus; OTU_72

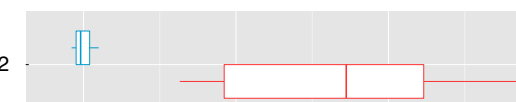

Firmicutes; Leuconostoc; OTU_209

Firmicutes; Mitsuokella; OTU_1282

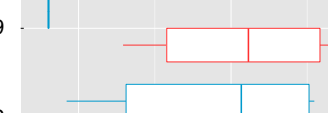

Firmicutes; Lactococcus; OTU_31

Actinobacteria; Collinsella; OTU_79

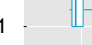

Firmicutes; Oscillospira; OTU_3
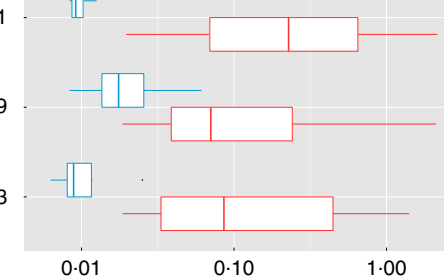

01

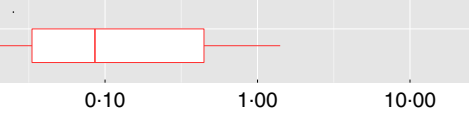

(c)

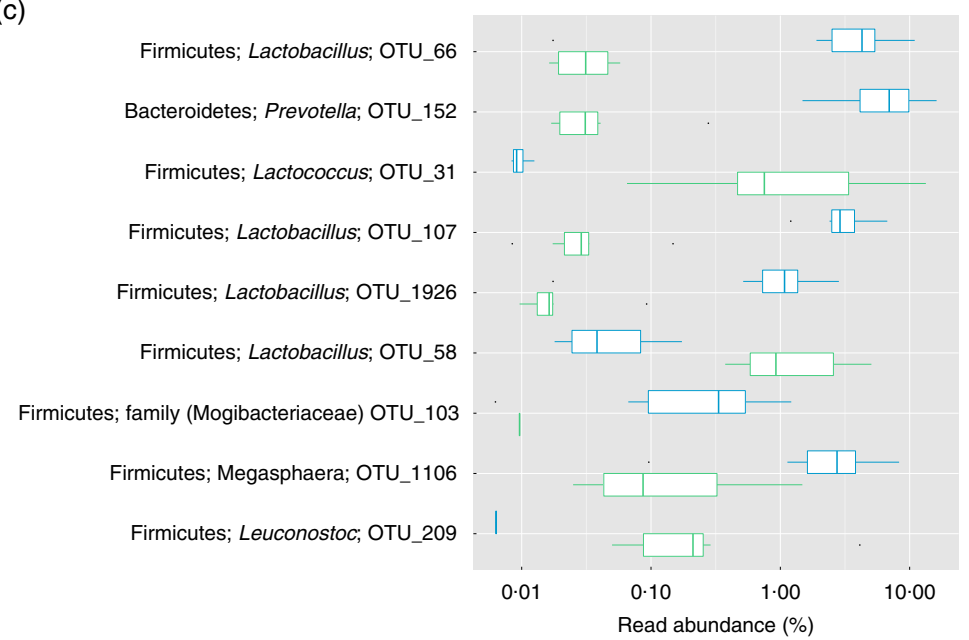

Fig. 4. (a) Principal component analysis of square root transformed Operational Taxonomical Units (OTU) abundances displaying principal components (PC)1 and 2; stomach digesta $(n 21)$, colostrum; $区$, milk replacer; $\square$, sow milk. Points are coloured for diet. Boxplots show the OTU significantly different between (b) sow milk fed (白) and bovine colostrum (白) fed piglets and (c) sow milk fed (白) and milk replacer (日) fed piglets. 
(a)

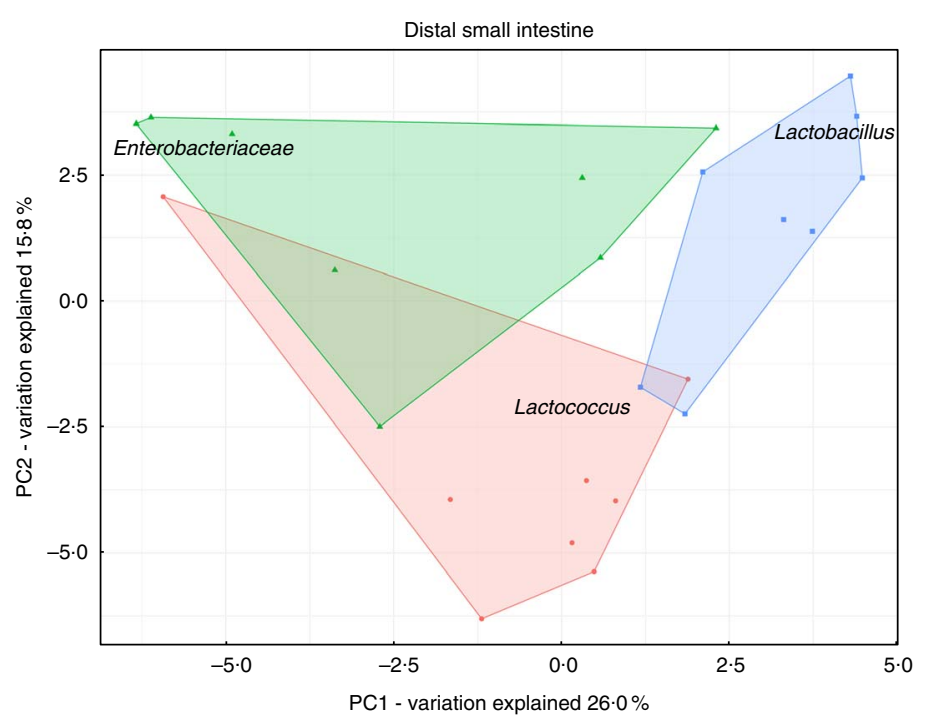

(b)

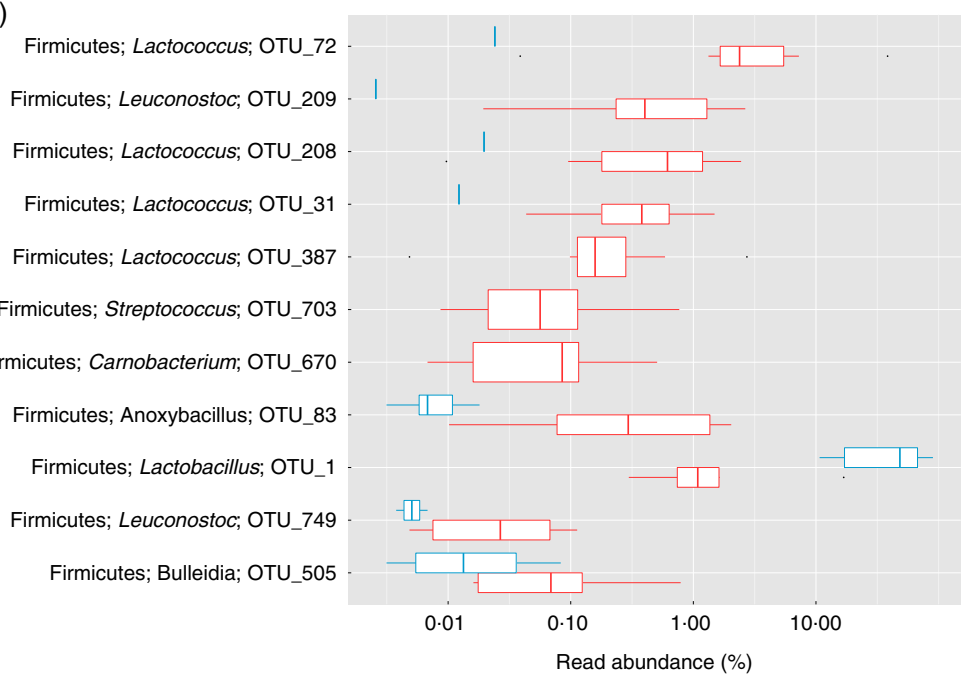

(c)

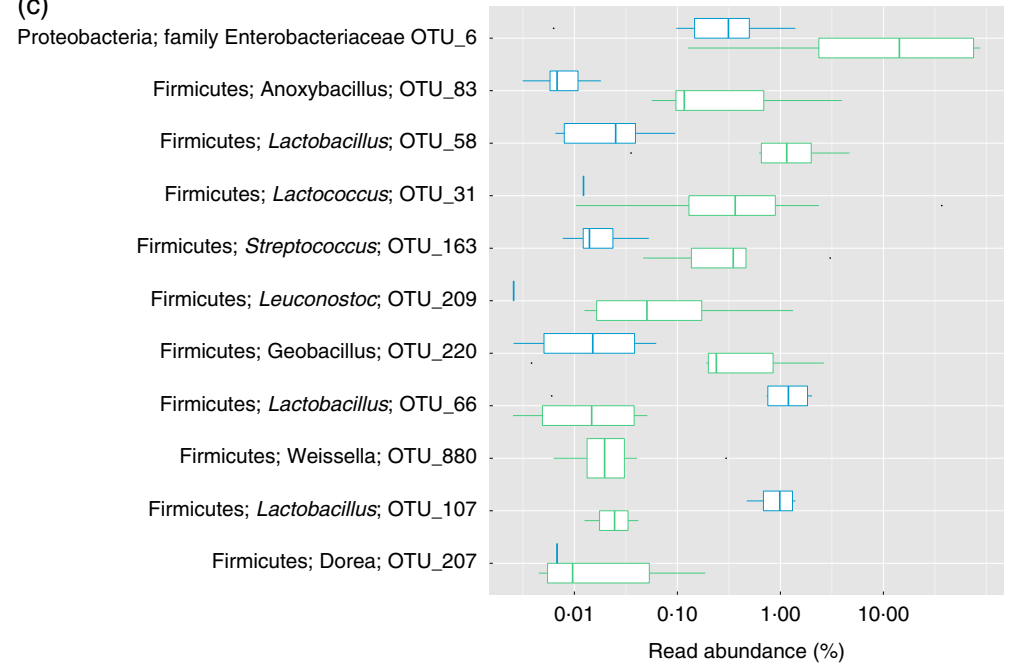

Fig. 5. (a) Principal component analysis of square root transformed Operational Taxonomical Units (OTU) abundances displaying principal components (PC)1 and 2; distal small intestinal digesta $(n 24) \square$, colostrum; $\square$, milk replacer; $\square$, sow milk. Points are coloured for diet. Boxplots show the OTU significantly different between (b) sow milk fed (巨) and bovine colostrum (巨) fed piglets and (c) sow milk fed (巨) and milk replacer (巨) fed piglets. 
(a)

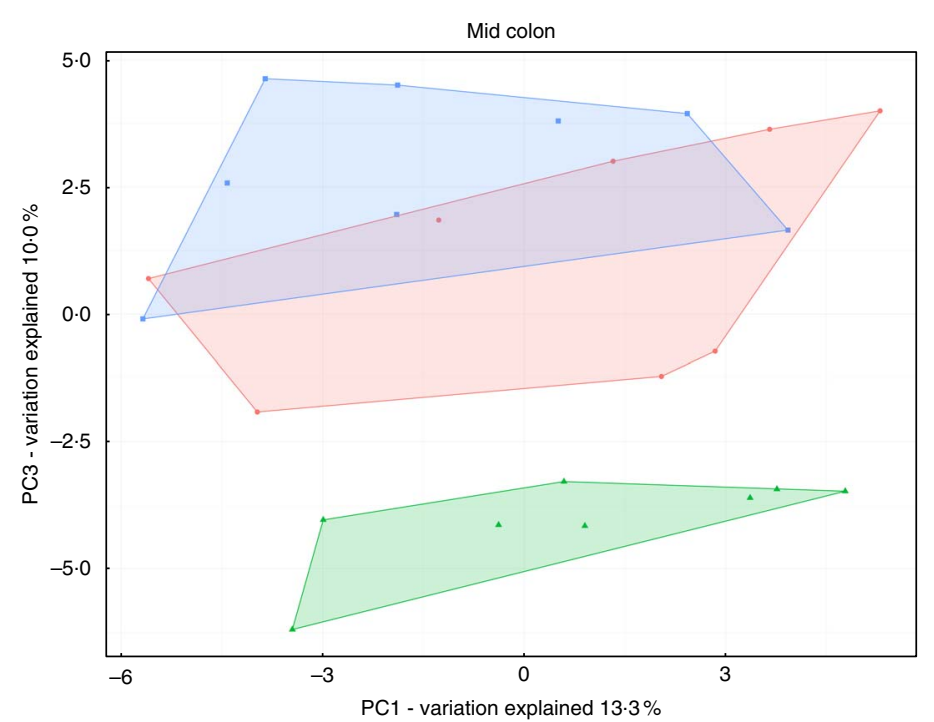

(b)

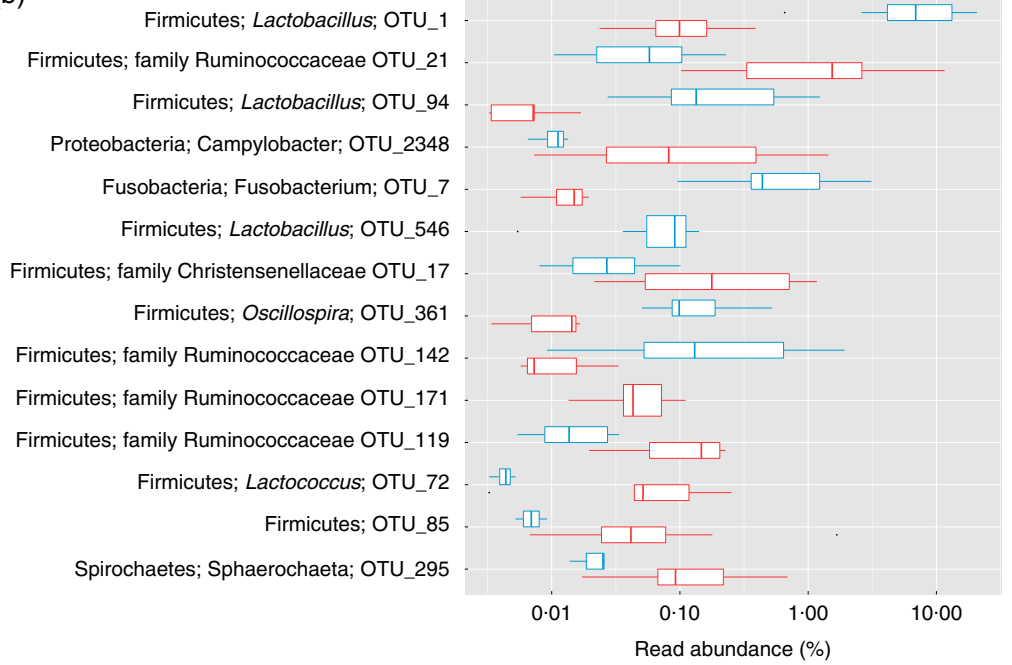

(c)

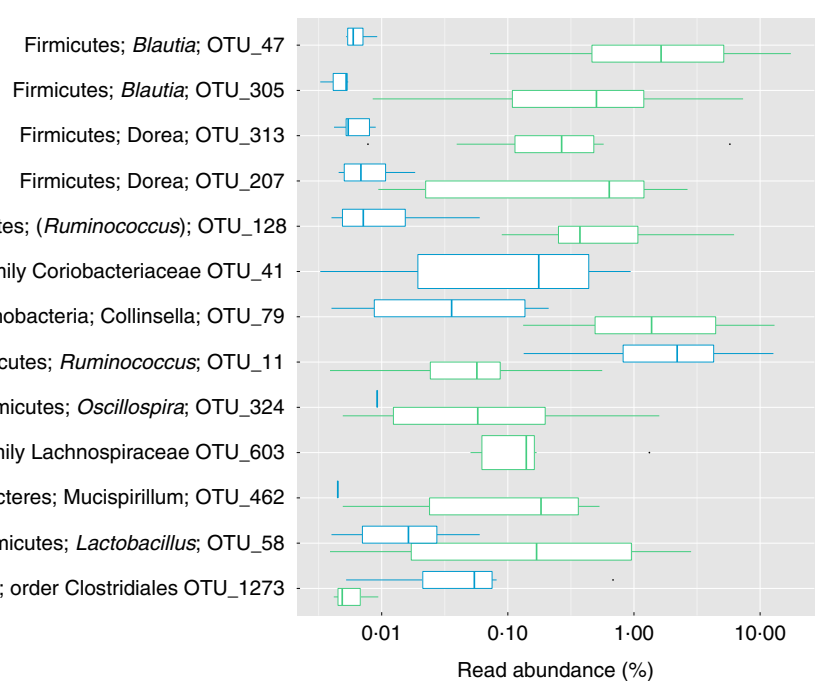

Fig. 6. (a) Principal component analysis of square root transformed Operational Taxonomical Units (OTU) abundances displaying principal components (PC)1 and 3 ; mid colon digesta $(n 24)$, colostrum; 7 , milk replacer;, , sow milk. Points are coloured for diet. Boxplots show the OTU significantly different between (b) sow milk fed (追) and bovine colostrum (追) fed piglets and (c) sow milk fed (户) and milk replacer (户) fed piglets. 
Table 3. SCFA concentrations $(\mu \mathrm{mol} / \mathrm{g}$ ) in faeces from piglets at $23,25,27$ and $30 \mathrm{~d}$ of age* (Least square means and $95 \%$ confidence intervals)

\begin{tabular}{|c|c|c|c|c|c|c|c|c|c|c|}
\hline \multirow[b]{3}{*}{ Items } & \multicolumn{6}{|c|}{ Dietary group $\dagger$} & & & & \\
\hline & \multicolumn{2}{|l|}{ SM } & \multicolumn{2}{|l|}{ MR } & \multicolumn{2}{|l|}{$\mathrm{BC}$} & & \multicolumn{3}{|c|}{$P$} \\
\hline & Least square mean & $95 \% \mathrm{Cl}$ & Least square mean & $95 \% \mathrm{Cl}$ & Least square mean & $95 \% \mathrm{Cl}$ & & D & A & $\mathrm{D} \times \mathrm{A}$ \\
\hline Acetic acid & y & & $y$ & & $\mathrm{z}$ & & & 0.0005 & 0.0008 & 0.06 \\
\hline Day 23 & 30.5 & $22 \cdot 8,38 \cdot 3$ & $28 \cdot 0$ & $20 \cdot 2,35 \cdot 7$ & $46 \cdot 3$ & $38.5,54.0$ & a & & & \\
\hline Day 25 & $42 \cdot 0$ & $34 \cdot 1,49 \cdot 8$ & 39.4 & $31 \cdot 5,47 \cdot 3$ & $57 \cdot 7$ & $49 \cdot 9,65.5$ & b & & & \\
\hline Day 27 & $37 \cdot 6$ & $29 \cdot 8,45 \cdot 4$ & $35 \cdot 1$ & $27 \cdot 2,42 \cdot 9$ & 53.4 & $45 \cdot 3,61 \cdot 5$ & $a, b$ & & & \\
\hline Day 30 & $45 \cdot 3$ & $37 \cdot 5,53 \cdot 1$ & $42 \cdot 8$ & $34.8,50 \cdot 7$ & $61 \cdot 1$ & $53 \cdot 1,69 \cdot 0$ & $\mathrm{~b}$ & & & \\
\hline Propionic acid & $\mathrm{y}$ & & y & & z & & & 0.002 & $<0.0001$ & 0.41 \\
\hline Day 23 & $7 \cdot 4$ & $5 \cdot 6,9 \cdot 7$ & 6.6 & $5 \cdot 0,8 \cdot 7$ & 11.9 & $9 \cdot 0,15 \cdot 6$ & a & & & \\
\hline Day 25 & $10 \cdot 9$ & $8 \cdot 2,14.4$ & $9 \cdot 8$ & $7 \cdot 4,12 \cdot 9$ & 17.5 & $13 \cdot 2,23 \cdot 0$ & $b$ & & & \\
\hline Day 27 & $13 \cdot 4$ & $10 \cdot 2,17 \cdot 7$ & $12 \cdot 0$ & $9 \cdot 1,15 \cdot 9$ & 21.5 & $16 \cdot 1,28 \cdot 7$ & b & & & \\
\hline Day 30 & $15 \cdot 4$ & $11 \cdot 7,20 \cdot 3$ & $13 \cdot 8$ & $10 \cdot 4,18 \cdot 3$ & $24 \cdot 7$ & $18 \cdot 6,32 \cdot 7$ & b & & & \\
\hline Butyric acid & $\mathrm{y}$ & & y & & z & & & 0.0008 & 0.002 & 0.11 \\
\hline Day 23 & 1.6 & $0 \cdot 8,2 \cdot 9$ & 0.9 & $0.4,1 \cdot 7$ & 3.9 & $2 \cdot 2,6 \cdot 8$ & a & & & \\
\hline Day 25 & 3.9 & $2 \cdot 2,6 \cdot 8$ & $2 \cdot 3$ & $1 \cdot 2,4 \cdot 1$ & $9 \cdot 0$ & $5 \cdot 2,15 \cdot 4$ & b & & & \\
\hline Day 27 & 3.5 & $2 \cdot 0,6 \cdot 1$ & $2 \cdot 1$ & $1 \cdot 1,3 \cdot 7$ & 8.2 & $4 \cdot 6,14 \cdot 3$ & b & & & \\
\hline Day 30 & 4.5 & $2.5,7.7$ & $2 \cdot 7$ & $1.4,4.8$ & $10 \cdot 3$ & $5 \cdot 9,17 \cdot 7$ & b & & & \\
\hline$A+P+B$ & y & & y & & $z$ & & & $<0.0001$ & 0.0002 & 0.09 \\
\hline Day 23 & $41 \cdot 8$ & $28 \cdot 4,55 \cdot 2$ & $34 \cdot 8$ & $21 \cdot 4,48 \cdot 2$ & $71 \cdot 3$ & $58.5,85.4$ & a & & & \\
\hline Day 25 & $61 \cdot 8$ & $48 \cdot 1,75 \cdot 4$ & $54 \cdot 8$ & $41.1,68.5$ & 91.9 & $78 \cdot 4,105.5$ & b & & & \\
\hline Day 27 & $59 \cdot 6$ & $46 \cdot 0,73 \cdot 1$ & $52 \cdot 6$ & $39 \cdot 0,66 \cdot 2$ & $89 \cdot 7$ & $75 \cdot 6,103 \cdot 8$ & b & & & \\
\hline Day 30 & $70 \cdot 8$ & $57 \cdot 2,84 \cdot 4$ & $63 \cdot 8$ & $49 \cdot 9,77 \cdot 7$ & 101.0 & $87 \cdot 2,114 \cdot 8$ & b & & & \\
\hline $\mathrm{IB}+\mathrm{IV}$ & & & & & & & & $<0.0001$ & 0.002 & 0.0004 \\
\hline Day 23 & 3.5 & $2 \cdot 2,5 \cdot 5$ & $2 \cdot 0$ & $1 \cdot 2,5 \cdot 5$ & $3.7^{\mathrm{A}}$ & $2 \cdot 4,5 \cdot 7$ & & & & \\
\hline Day 25 & $3.3^{\mathrm{b}}$ & $2 \cdot 1,5 \cdot 3$ & $3.5^{\mathrm{b}}$ & $2 \cdot 2,5 \cdot 3$ & $10 \cdot 8^{\mathrm{a}, \mathrm{B}}$ & $7 \cdot 0,16 \cdot 4$ & & & & \\
\hline Day 27 & $3.8^{\mathrm{b}}$ & $2.4,5.9$ & $2 \cdot 0^{\mathrm{b}}$ & $1.2,5.9$ & $11.9^{\mathrm{a}, \mathrm{B}}$ & $7 \cdot 3,19 \cdot 4$ & & & & \\
\hline Day 30 & $5.0^{\mathrm{b}}$ & $3.2,7 \cdot 7$ & $3.0^{\mathrm{b}}$ & $1.8,7 \cdot 7$ & $12 \cdot 9^{\mathrm{a}, \mathrm{B}}$ & $8 \cdot 3,20 \cdot 0$ & & & & \\
\hline
\end{tabular}

SM, sow milk; MR, milk replacer; BC, bovine colostrums; $D$, diet; $A$, age; $A+P+B$, acetic + propionic + butyric acid; IB + IV, iso-butyric + iso-valeric acid

$y, z$ Columns with different letters within a SCFA group are significantly different.

$\mathrm{a}, \mathrm{b}$ Mean values within a row with unlike superscript letters are significantly different.

$A, B$ Mean values within a column with unlike superscript letters are significantly different.

a,b Rows with different letters within a SCFA group are significantly different.

* Detection levels (mmol/kg): 1.1 (acetic acid), 0.5 (propionic acid), 0.3 (butyric acid), 0.3 (iso-butyric acid) and 0.3 (iso-valeric acid)

$\dagger$ Number of piglets: $\mathrm{BC}=12$, except day $5(n 9)$ and day 8 ( $n$ 11); MR $=12$, except day $3(n 11)$ and day $8(n 10)$; SM=12, except day $3(n 10)$.

meat and fish ${ }^{(39)}$; and Streptococcus sp. has previously been isolated from the gastrointestinal tract of pigs ${ }^{(40)}$. BC-fed piglets furthermore had a higher abundance of Mitsuokella in the stomach digesta, which previously has been isolated from the stomach and colon digesta of pigs ${ }^{(40,41)}$. Levine et al. ${ }^{(42)}$ reported an inhibiting effect of Mitsuokella jalaludinii on Salmonella typhimurium. They found that the combined effect of acetic, lactic and succinic acid produced by $M$. jalaludinii during fermentation in vitro, and the accompanied decrease in $\mathrm{pH}$, was able to inhibit the growth of and cellular invasion by $S$. typhimurium. The authors therefore proposed $M$. jalaludinii to have potential as a probiotic species. In our study, we were not able to determine the Misuokella species in question, however, blasting OTU_1282 revealed a $97 \%$ similarity to $M$. jalaludinii. Hence, assuming that it was $M$. jalaludinii, it could be speculated on the aforementioned beneficial effects. Hence, the presence of a potentially probiotic bacteria in BC-fed piglets may have enhanced resistance against pathogens (such as Enterotoxigenic Escherichia coli (ETEC)) and intestinal mucosal integrity in these animals. Sugiharto et al. ${ }^{(14)}$, analysing samples from the animals included in the present study, reported fewer $E$. coli and a lower expression of TLR- 4 and IL-2 in the small intestinal tissue of BC-fed piglets compared with MR-fed piglets, which furthermore suggests a beneficial effect of the $\mathrm{BC}$ diet. Whether M. jalaludinii or other bacteria contributed to these effects cannot be elucidated here.
16S rRNA gene sequencing on bacterial DNA from distal small intestinal digesta revealed that MR-fed piglets had a higher abundance of Enterobacteriaceae when compared to SM-fed piglets. ETEC belongs to the Enterobacteriaceae family and is an intestinal pathogen frequently observed after weaning causing post-weaning diarrhoea. ETEC produces haemolysin, a virulence factor enabling haemolysis of erythrocytes ${ }^{(43)}$. By bacterial culture, we observed a higher number of haemolytic bacteria in digesta from MR-fed compared with SM- and BC-fed piglets. The higher abundance of Enterobacteriaceae observed using $16 \mathrm{~S}$ rRNA gene sequencing could therefore represent a higher abundance of potential intestinal pathogens such as ETEC. This is further supported by the higher diarrhoea incidence observed in MR- compared with BC- and SM-fed piglets. The improved faecal consistency in BC-fed piglets is in accordance with results by Huguet et $a l^{(15)}$ who found an improved sanitary status and faecal consistency in weanling pigs supplemented with BC. The fact that BC-fed piglets in the present study experienced less diarrhoea than MR-fed piglets could be due to the effect of immunoglobulins and growth promoting factors present in colostrum. The high content of IgG provides passive immune protection to the newborn calf ${ }^{(44)}$ and growth factors stimulate enterocyte proliferation ${ }^{(8)}$, potentially resulting in a less disturbed intestinal barrier. BC has furthermore been reported to inhibit E. coli growth in vitro ${ }^{(36)}$. De Vos et al. ${ }^{(33)}$ investigated the effect 
Table 4. Counts (log colony-forming units/g) of selected microbial groups in digesta from the gastrointestinal tract of 30-d old piglets (end of experiment) ${ }^{\star} \dagger$ (Least square means and $95 \%$ confidence intervals)

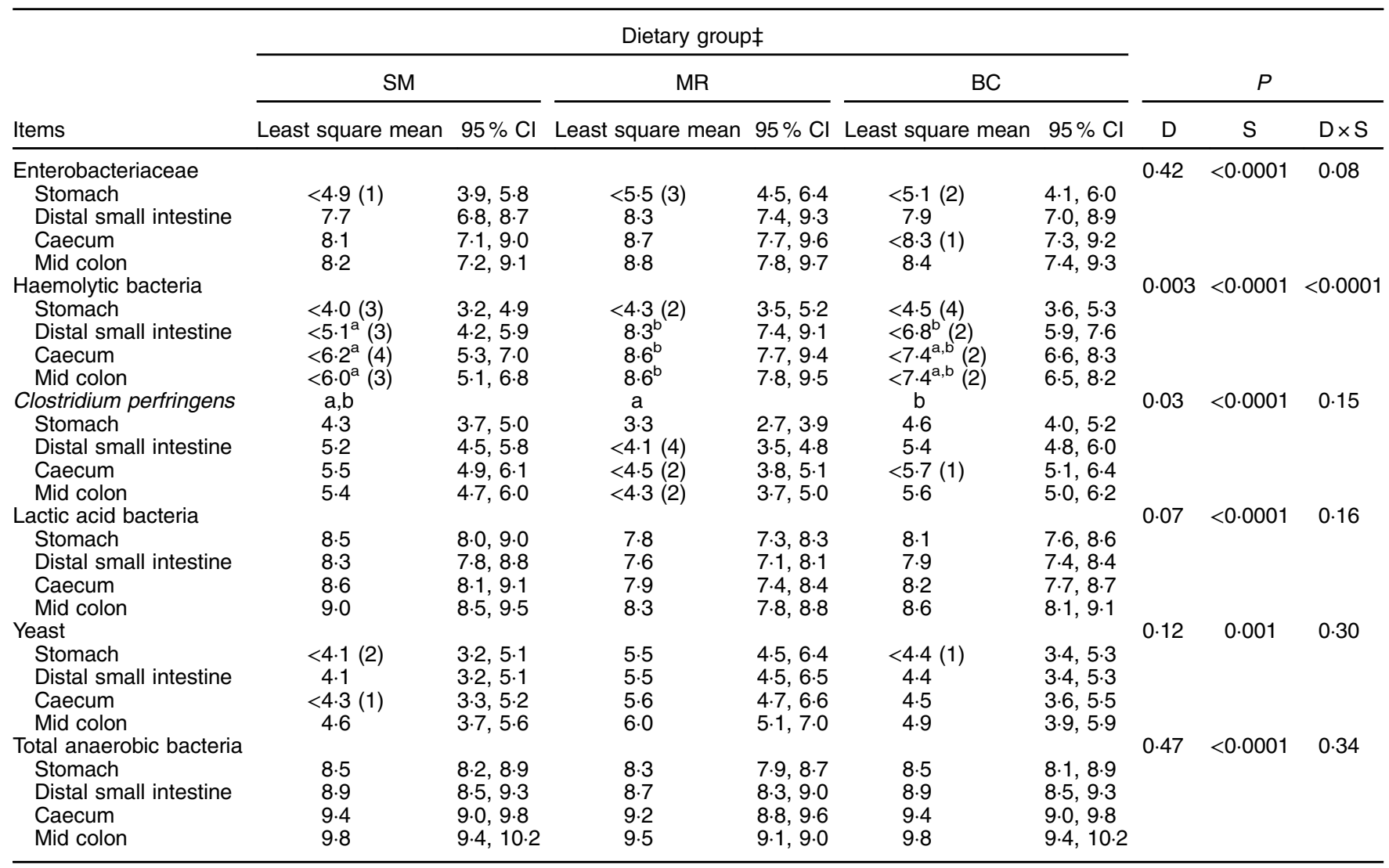

SM, sow milk; MR, milk replacer; BC, bovine colostrums; D, diet; S, intestinal segment; <, indicates that at least one of the observations used to calculate the least square mean was below detection level.

$a, b$ Mean values within a row with unlike superscript letters are significantly different.

a,b Columns with different letters within a microbial group are significantly different.

* Numbers in brackets indicate how many samples were below detection levels.

$\dagger$ Samples from the stomach, distal small intestine, caecum and mid colon were analysed.

$\ddagger$ Number of piglets: $\mathrm{BC}=4 ; \mathrm{MR}=4 ; \mathrm{SM}=4$.

of feeding 3-d-old piglets a milk replacer supplemented with a $\mathrm{BC}$ whey fraction on the intestinal permeability, and found an increased occludin gene expression and decreased mannitol absorption, thus indicating an effect on the enterocyte-toenterocyte adherence and hence gut barrier function.

The change in genera belonging to LAB in BC-fed piglets, and the rise in the number of potentially pathogenic Enterobacteriaceae in MR-fed piglets, confirms that BC in fact is able to promote a gut microbiota inhabited by host-beneficial bacteria. The observation in MR-fed piglets agrees with previous piglet studies, where MR-feeding was found to be accompanied by a rise in Enterobacteria ${ }^{(45)}$. In agreement with the general belief that mother's own milk is the preferred nutrition for suckling piglets, it was obvious that sow milk was superior to the investigated experimental diets. However, when mother's milk is not sufficiently available, the loss of crucial protective compounds may be counteracted by some of the bioactive components found in BC. This potential can also be taken advantage of when piglets are weaned. $\mathrm{BC}$ has previously been shown to have a beneficial effect on both weight gain and feed intake in piglets post-weaning ${ }^{(15,46)}$. The apparent ability of BC to reduce the number of Enterobacteriaceae in digesta suggests that $\mathrm{BC}$ has the potential to reduce the intestinal colonisation of ETEC. This is supported by results from the current animal study published by Sugiharto et al. ${ }^{(14)}$ who confirmed that the number of mucosa-associated $E$. coli and haemolytic bacteria was reduced in the jejunal and ileal tissue of BC-fed piglets. Hence, feeding $\mathrm{BC}$ during the transition period related to weaning may be a promising strategy to enhance gut health of newly weaned piglets.

Despite the high content of growth factors reported in BC, we found no difference in growth performance between BC-fed and MR-fed piglets over the period of 1 week post-weaning. The present study, however, was not designed as a performance study per se. The study by De Vos et al. ${ }^{(33)} \mathrm{did}$ not obtain any effect on growth performance when feeding BCsupplemented milk replacer to 3-10 d-old-piglets. Other studies have reported an increased growth performance when piglets were fed weaning diets supplemented with BC compared with unsupplemented diets ${ }^{(15,46)}$.

The chemical compositions of the diets were very different and with the most noticeably difference being the protein content. The high-protein content of $\mathrm{BC}$ was attributed to the high concentration of immunoglobulins ${ }^{(12)}$. As branched SCFA (BCFA) 
Table 5. Organic acid concentrations $(\mu \mathrm{mol} / \mathrm{g})$ in digesta from four segments of the gastrointestinal tract of $30 \mathrm{~d}$-old piglets (end of experiment) ${ }^{*} \dagger$ (Least square means and $95 \%$ confidence intervals)

\begin{tabular}{|c|c|c|c|c|c|c|c|c|c|}
\hline \multirow[b]{3}{*}{ Items } & \multicolumn{6}{|c|}{ Dietary group } & & & \\
\hline & \multicolumn{2}{|l|}{ SM } & \multicolumn{2}{|l|}{ MR } & \multicolumn{2}{|l|}{$\mathrm{BC}$} & \multicolumn{3}{|c|}{$P$} \\
\hline & Least square mean & $95 \% \mathrm{Cl}$ & Least square mean & $95 \% \mathrm{Cl}$ & Least square mean & $95 \% \mathrm{Cl}$ & D & S & $D \times S$ \\
\hline Lactic acid§ & & & & & & & 0.11 & 0.64 & 0.09 \\
\hline Stomach & $9 \cdot 0$ & $4 \cdot 1,17 \cdot 5$ & $7 \cdot 2$ & $3 \cdot 2,14 \cdot 5$ & $2 \cdot 8$ & $0.7,6.6$ & & & \\
\hline Distal small intestine & $8 \cdot 7$ & $4 \cdot 0,17-1$ & $7 \cdot 1$ & $3 \cdot 1,14 \cdot 2$ & $2 \cdot 8$ & $0.7,6.5$ & & & \\
\hline Acetic acid & & & & & & & 0.42 & $<0.0001$ & 0.46 \\
\hline Stomach & 3.4 & $1 \cdot 6,6 \cdot 3$ & $2 \cdot 7$ & $1 \cdot 2,5 \cdot 2$ & $4 \cdot 1$ & $2 \cdot 0,7 \cdot 5$ & & & \\
\hline Distal small intestine & $7 \cdot 1$ & $3.8,12 \cdot 5$ & $5 \cdot 8$ & $3 \cdot 0,10 \cdot 4$ & $8 \cdot 3$ & $4.6,14.6$ & & & \\
\hline Caecum & 52.5 & $31 \cdot 0,88 \cdot 5$ & $44 \cdot 1$ & $25 \cdot 7,75 \cdot 2$ & $61 \cdot 0$ & $36 \cdot 1,102 \cdot 7$ & & & \\
\hline Mid colon & 44.0 & $26.0,73.9$ & 36.9 & $21 \cdot 7,62 \cdot 3$ & 51.2 & $30 \cdot 3,85 \cdot 8$ & & & \\
\hline Propionic acid & & & & & & & 0.10 & $<0.0001$ & 0.30 \\
\hline Stomach & 2.5 & $1 \cdot 2,4.8$ & 1.5 & $0.6,3.0$ & $3 \cdot 3$ & $1 \cdot 7,6 \cdot 2$ & & & \\
\hline Distal small intestine & 0.8 & $0.2,1.8$ & 0.4 & $0.0,1.0$ & $1 \cdot 2$ & $0.4,2.4$ & & & \\
\hline Caecum & $14 \cdot 6$ & $8 \cdot 0,26 \cdot 3$ & 9.4 & $5 \cdot 0,17 \cdot 4$ & $18 \cdot 7$ & $10 \cdot 3,33 \cdot 6$ & & & \\
\hline Mid colon & 17.4 & $9 \cdot 7,31 \cdot 1$ & 11.3 & $6 \cdot 1,20 \cdot 3$ & $22 \cdot 3$ & $12 \cdot 4,39 \cdot 7$ & & & \\
\hline Butyric acid\| & & & & & & & 0.56 & 0.64 & 0.13 \\
\hline Caecum & $6 \cdot 9$ & $2 \cdot 6,11 \cdot 3$ & $5 \cdot 6$ & $1 \cdot 1,10 \cdot 1$ & $8 \cdot 2$ & $3 \cdot 8,12 \cdot 5$ & & & \\
\hline Mid colon & $6 \cdot 8$ & $2 \cdot 5,11 \cdot 2$ & 5.5 & $1 \cdot 1,9.9$ & $8 \cdot 1$ & $3.7,12 \cdot 4$ & & & \\
\hline$A+P+B$ & & & & & & & 0.26 & $<0.0001$ & 0.04 \\
\hline Stomach & $6 \cdot 8$ & $3 \cdot 7,12 \cdot 4$ & 4.9 & $2 \cdot 6,8 \cdot 9$ & $7 \cdot 7$ & $4 \cdot 2,14 \cdot 2$ & & & \\
\hline Distal small intestine & 8.4 & $4 \cdot 6,15 \cdot 4$ & $6 \cdot 0$ & $3 \cdot 3,11 \cdot 1$ & $9 \cdot 6$ & $5 \cdot 2,17 \cdot 6$ & & & \\
\hline Caecum & $76 \cdot 9$ & $41 \cdot 7,141 \cdot 6$ & $55 \cdot 0$ & $29 \cdot 4,102 \cdot 8$ & $87 \cdot 6$ & $47 \cdot 6,161 \cdot 3$ & & & \\
\hline Mid colon & 71.9 & $39 \cdot 2,131 \cdot 7$ & $51 \cdot 4$ & $28 \cdot 0,94.5$ & $81 \cdot 9$ & $44 \cdot 7,150 \cdot 0$ & & & \\
\hline $\mathrm{IB}+\mathrm{IV} \|$ & & & & & & & 0.02 & 0.65 & 0.03 \\
\hline $\begin{array}{l}\text { Caecum } \\
\text { Mid colon }\end{array}$ & $\begin{array}{l}5 \cdot 8^{\mathrm{a}} \\
4 \cdot 1^{\mathrm{a}, \mathrm{b}}\end{array}$ & $\begin{array}{l}3 \cdot 3,10 \cdot 2 \\
2 \cdot 3,7 \cdot 3\end{array}$ & $\begin{array}{l}1 \cdot 7^{\mathrm{b}} \\
2 \cdot 2^{\mathrm{a}}\end{array}$ & $\begin{array}{l}0.8,3 \cdot 2 \\
1.24 .0\end{array}$ & $\begin{array}{l}4 \cdot 7^{\mathrm{a}, \mathrm{b}} \\
10 \cdot 0^{\mathrm{b}}\end{array}$ & $\begin{array}{l}2 \cdot 6,8 \cdot 3 \\
5 \cdot 7 \cdot 17 \cdot 5\end{array}$ & & & \\
\hline
\end{tabular}

SM, sow milk; MR, milk replacer; BC, bovine colostrum; $D$, diet; $S$, intestinal segment; $A+P+B$, acetic + propionic + butyric acid; IB + IV, iso-butyric + iso-valeric acid.

$\mathrm{a}, \mathrm{b}$ Mean values with unlike superscript letters within a row are significantly different.

* Detection levels (mmol/kg): 1.9 (lactic acid), 1.1 (acetic acid), 0.5 (propionic acid), 0.3 (butyric acid), 0.3 (iso-butyric acid) and 0.3 (iso-valeric acid).

$\dagger$ Samples from the stomach, distal small intestine, caecum and mid colon were analysed.

$\ddagger$ Number of piglets: $\mathrm{BC}=4 ; \mathrm{MR}=4 ; \mathrm{SM}=4$.

$\S$ Samples from the caecum and mid colon had values below detection level.

\| Samples from the stomach and distal small intestine had values below detection level.

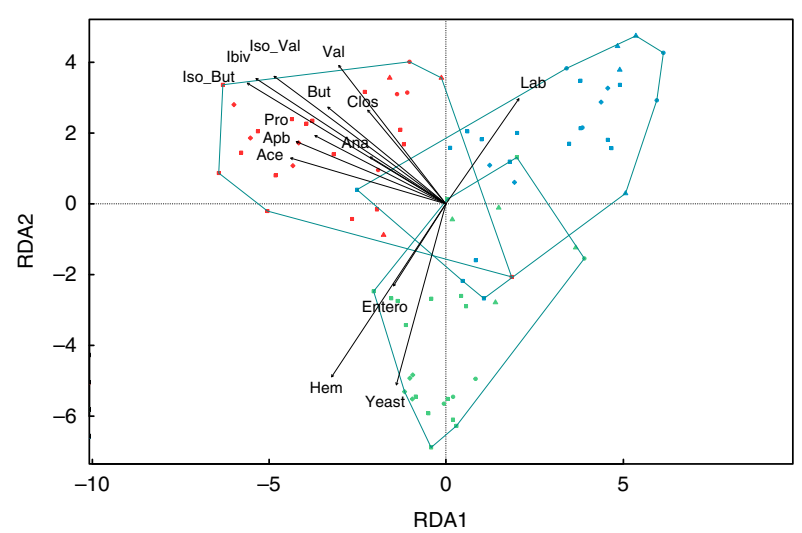

Fig. 7. Constrained redundancy analysis of square root transformed Operational Taxonomical Units (OTU) abundances fitted with microbial culture and SCFA data ( $n$ 115), displaying RDA1 and RDA2. The arrows point toward the highest values and the length of the arrow indicates the parameters significance. Ana, total anaerobic bacteria; Clos, Clostridium perfringens; Entero, Enterobacteriaceae; Hem, haemolytic bacteria; Lab, lactic acid bacteria; Ace, acetic acid; Apb, acetic + propionic + butyric acid; But, butyric acid; Pro, propionic acid; Iso_But, iso-butyric acid; Iso_Val, iso-valeric acid; Ibiv, iso-butyric + iso-valeric acid; Val, valeric acid. O, Colostrum; O, milk replacer; $\bigcirc$, sow milk; $\boldsymbol{\Delta}$, stomach; $\boldsymbol{O}$, distal small intestine; $\boldsymbol{\rangle}$, mid colon; faeces.

are indicators of protein fermentation ${ }^{(47,48)}$, the higher concentrations of iso-valeric and iso-butyric acid in faeces and digesta from BC-fed piglets most likely reflect that these piglets were fed a highprotein diet. Protein fermentation, however, also produces unwanted and potentially toxic compounds such as ammonia ${ }^{(49)}$, amines, phenols and indols ${ }^{(48)}$. Other reports have shown an increased shedding of $E$. coli from pigs fed high-protein diets ${ }^{(50)}$ and a decreased ileal cytokine response upon lipopolysaccharide stimulation in pigs fed a high-protein milk formula in early life ${ }^{(51)}$. In the present study, we did not see any association between the higher protein content in the BC diet and an increased shedding of pathogenic bacteria as $E$. coli. Besides a higher concentration of BCFA, feeding BC also resulted in higher digesta concentrations of the SCFA acetic, propionic and butyric acid, which are considered to be beneficial to the host ${ }^{(48)}$.

\section{Conclusion}

In conclusion, feeding $\mathrm{BC}$ to piglets in the immediate post-weaning period reduced the number of potential pathogenic ETEC in the intestinal content and faeces when compared with piglets fed MR. Especially the distal small intestinal microbiota of piglets fed BC had a closer resemblance to that of piglets fed SM than had the microbiota of piglets fed MR. As our study does not enable us to account for the long-term effects of feeding BC, the effects of increased protein fermentation, reflected by higher BCFA concentrations in BC-fed piglets, should be investigated in the future.

\section{Acknowledgements}

The authors thank Karin Durup, Mette Lykkegaard, Mette Kvist and Karin Johansen for their skillful technical assistance during the course of the experiment. 
The Danish Council for Strategic Research funded the experiment through the NEOMUNE consortium together with the Graduate School of Science and Technology, Aarhus University, Denmark. The bovine colostrum powder was partly sponsored by The European Colostrum Industry S.A. The funders had no role in the design, analysis or writing of this article.

Authors contributed as follows: A.-S. R. P. conducted the animal experiment, performed sample and data analyses and drafted the manuscript. S. S. conducted the animal experiment. N. C. designed the experiment, contributed to the conduction of the animal experiment and assisted with data analysis. N. d. J and J. L. N. performed data analysis. C. L. designed the experiment. All authors have revised and accepted the final manuscript.

There were no conflicts of interest.

\section{Supplementary material}

For supplementary material/s referred to in this article, please visit https://doi.org/10.1017/S0007114517000216

\section{References}

1. De Vos M, Che L, Huygelen V, et al. (2014) Nutritional interventions to prevent and rear low-birthweight piglets. J Anim Physiol Anim Nutr 98, 609-619.

2. De Vos M, Huygelen V, Willemen S, et al. (2014) Artificial rearing of piglets: effects on small intestinal morphology and digestion capacity. Livest Sci 159, 165-173.

3. Mackie RI, Sghir A \& Gaskins HR (1999) Developmental microbial ecology of the neonatal gastrointestinal tract. $A m J$ Clin Nutr 69, 1035S-1045S.

4. Buddington RK \& Sangild PT (2011) Development of the mammalian gastrointestinal tract, the resident microbiota, and the role of diet in early life. J Anim Sci 89, 1506-1519.

5. Sarker SA \& Gyr K (1992) Non-immunological defence mechanisms of the gut. Gut 33, 987-993.

6. Cummings J, Antoine J, Azpiroz F, et al. (2004) PASSCLAIM: gut health and immunity. Eur J Nutr 43, II118-II173.

7. Guarner F \& Malagelada JR (2003) Gut flora in health and disease. Lancet 361, 512-519.

8. Pakkanen R \& Aalto J (1997) Growth factors and antimicrobial factors of bovine colostrum. Int Dairy J 7, 285-297.

9. Theil PK, Lauridsen C \& Quesnel H (2014) Neonatal piglet survival: impact of sow nutrition around parturition on fetal glycogen deposition and production and composition of colostrum and transient milk. Animal 8, 1021-1030.

10. Lalles JP, Bosi P, Janczyk P, et al. (2009) Impact of bioactive substances on the gastrointestinal tract and performance of weaned piglets: a review. Animal 3, 1625-1643.

11. Sugiharto SJ, Jensen BB \& Lauridsen KHC (2015) Prevention of enterotoxigenic Escherichia coli infections in pigs by dairy-based nutrition. Cab Rev 10, 1-16.

12. Boudry C, Dehoux JP, Portetelle D, et al. (2008) Bovine colostrum as a natural growth promoter for newly weaned piglets: a review. Biotechnol Agron Soc Environ 12, 157-170.

13. Støy ACF, Heegaard PMH, Thymann T, et al. (2014) Bovine colostrum improves intestinal function following formula-induced gut inflammation in preterm pigs. Clin Nutr 33, 322-329.

14. Sugiharto S, Poulsen ASR, Canibe N, et al. (2015) Effect of bovine colostrum feeding in comparison with milk replacer and natural feeding on the immune responses and colonisation of enterotoxigenic Escherichia coli in the intestinal tissue of piglets. Br J Nutr 113, 923-934.
15. Huguet A, Le Dividich J \& Le Huerou-Luron I (2012) Improvement of growth performance and sanitary status of weaned piglets fed a bovine colostrum-supplemented diet. J Anim Sci 90, 1513-1520.

16. Huguet A, Le Normand L, Fauquant J, et al. (2007) Influence of bovine colostrum on restoration of intestinal mucosa in weaned piglets. Livest Sci 108, 20-22.

17. Lauridsen C \& Danielsen V (2004) Lactational dietary fat levels and sources influence milk composition and performance of sows and their progeny. Livest Prod Sci 91, 95-105.

18. Aguinaga MA, Gomez-Carballar F, Nieto R, et al. (2011) Production and composition of Iberian sow's milk and use of milk nutrients by the suckling Iberian piglet. Animal 5, 1390-1397.

19. Canibe N, Hojberg O, Badsberg JH, et al. (2007) Effect of feeding fermented liquid feed and fermented grain on gastrointestinal ecology and growth performance in piglets. J Anim Sci 85 , 2959-2971.

20. Holdeman LV, Cato EP \& Moore EC (1977) Anaerobe Laboratory Manual. Blacksburg, VA: Polytechnic Institute and State University.

21. Miller TL \& Wolin MJ (1974) Serum bottle modification of hungate technique for cultivating obligate anaerobes. Appl Microbiol 27, 985-987.

22. Bolger AM, Lohse M \& Usadel B (2014) Trimmomatic: a flexible trimmer for Illumina sequence data. Bioinformatics 30, 2114-2120.

23. Magoc T \& Salzberg SL (2011) FLASH: fast length adjustment of short reads to improve genome assemblies. Bioinformatics 27, 2957-2963.

24. Edgar RC (2013) UPARSE: highly accurate OTU sequences from microbial amplicon reads. Nat Methods 10, 996-1000.

25. Caporaso JG, Kuczynski J, Stombaugh J, et al. (2010) QIIME allows analysis of high-throughput community sequencing data. Nat Methods 7, 335-336.

26. Albertsen M, Karst SM, Ziegler AS, et al. (2015) Back to basics the influence of DNA extraction and primer choice on phylogenetic analysis of activated sludge communities. PLOS ONE 10, e0132783.

27. Oksanen JGB, Kindt F, Legendre R, et al. (2015) vegan: Community Ecology Package. $R$ package version 2.3-2. https://cran.r-project.org/src/contrib/Archive/vegan/.

28. Love MI, Huber W \& Anders S (2014) Moderated estimation of fold change and dispersion for RNA-seq data with DESeq2. Genome Biol 15, 550.

29. Bates D, Maechler M, Bolker B, et al. (2014) lme4: linear mixed-effects models using Eigen and S4. R package version 1.1.7. http://CRAN.R-project.org/package $=\operatorname{lme} 4 \quad$ (accessed September 2015).

30. Halekoh U \& Højsgaard S (2014) A Kenward-Roger approximation and parametric bootstrap methods for tests in linear mixed models the R Package pbkrtest. J Stat Softw 59.

31. Hothorn T, Bretz F. \& Westfall P (2008) Simultaneous inference in general parametric models. Biometrical J 50, 346-363.

32. Houe HE \& Toft AKN (2004) Introduction to Veterinary Epidemiology, 1st ed. Copenhagen: Biofolia.

33. De Vos M, Huygelen V, Van Raemdonck G, et al. (2014) Supplementing formula-fed piglets with a low molecular weight fraction of bovine colostrum whey results in an improved intestinal barrier. J Anim Sci 92, 3491-3501.

34. Lalles J, Bosi P, Smidt H, et al. (2007) Nutritional management of gut health in pigs around weaning. Proc Nutr Soc 66, 260-268.

35. Looft T, Allen HK, Cantarel BL, et al. (2014) Bacteria, phages and pigs: the effects of in-feed antibiotics on the microbiome at different gut locations. ISME J 8, 1566-1576.

36. Champagne CP, Raymond Y, Pouliot Y, et al. (2014) Effect of bovine colostrum, cheese whey, and spray-dried porcine 
plasma on the in vitro growth of probiotic bacteria and Escherichia coli. Can J Microbiol 60, 287-295.

37. McGrath BA, Fox PF, McSweeney PLH, et al. (2016) Composition and properties of bovine colostrum: a review. Dairy Sci Technol 96, 133-158.

38. Dobson A, Crispie F, Rea MC, et al. (2011) Fate and efficacy of lacticin 3147-producing Lactococcus lactis in the mammalian gastrointestinal tract. FEMS Microbiol Ecol 76, 602-614.

39. Leisner JJ, Laursen BG, Prevost H, et al. (2007) Carnobacterium: positive and negative effects in the environment and in foods. FEMS Microbiol Rev 31, 592-613.

40. Mikkelsen LL, Hojberg O \& Jensen BB (2007) Coarse structured feed stimulates members of the genera Lactobacillus and Mitsuokella as well as propionate and butyrate producers in the pig stomach. Livest Sci 109, 153-156.

41. Canibe N, Hojberg O, Hojsgaard S, et al. (2005) Feed physical form and formic acid addition to the feed affect the gastrointestinal ecology and growth performance of growing pigs. J Anim Sci $\mathbf{8 3}$, $1287-1302$.

42. Levine UY, Bearson SMD \& Stanton TB (2012) Mitsuokella jalaludinii inhibits growth of Salmonella enterica serovar Typhimurium. Vet Microbiol 159, 115-122.

43. Fairbrother JM, Nadeau E \& Gyles CL (2005) Escherichia coli in postweaning diarrhea in pigs: an update on bacterial types, pathogenesis, and prevention strategies. Anim Health Res Rev 6, 17-39.

44. Wheeler TT, Hodgkinson AJ, Prosser CG, et al. (2007) Immune components of colostrum and milk - a historical perspective. J Mammary Gland Biol Neoplasia 12, 237-247.
45. Yeruva L, Spencer NE, Saraf MK, et al. (2016) Formula diet alters small intestine morphology, microbial abundance and reduces VE-cadherin and IL-10 expression in neonatal porcine model. BMC Gastroenterol 16, 40 .

46. Boudry C, Dehoux JP, Wavreille J, et al. (2008) Effect of a bovine colostrum whey supplementation on growth performance, faecal Escherichia coli population and systemic immune response of piglets at weaning. Animal 2, 730-737.

47. Macfarlane GT, Gibson GR, Beatty E, et al. (1992) Estimation of short-chain fatty acid production from protein by human intestinal bacteria based on branched-chain fatty acid measurements. FEMS Microbiol Ecol 101, 81-88.

48. Rist VTS, Weiss E, Eklund M, et al. (2013) Impact of dietary protein on microbiota composition and activity in the gastrointestinal tract of piglets in relation to gut health: a review. Animal 7, 1067-1078.

49. Bikker P, Dirkzwager A, Fledderus J, et al. (2007) Dietary protein and fermentable carbohydrates contents influence growth performance and intestinal characteristics in newly weaned pigs. Livest Sci 108, 194-197.

50. Heo JM, Kim JC, Hansen CF, et al. (2008) Effects of feeding low protein diets to piglets on plasma urea nitrogen, faecal ammonia nitrogen, the incidence of diarrhoea and performance after weaning. Arch Anim Nutr 62, 343-358.

51. Chatelais L, Jamin A, Gras-Le Guen C, et al. (2011) The level of protein in milk formula modifies ileal sensitivity to LPS later in life in a piglet model. PLOS ONE 6, e19594. 